\title{
La tipología de los mensajes en el suplemento "Paraninfo" de la Universidad de Alicante: temáticas, públicos objetivos y finalidad de los mensajes
}

\author{
MHCJ no 4 | Año 2013 \\ Artículo nㅇ (41) \\ Páginas 31 a 64 \\ mhci.es
}

Doctora Tatiana Hidalgo-Marí | thm@alu.ua.es

\section{Palabras clave}

Comunicación institucional, prensa, análisis de contenido, agenda setting, Universidad de Alicante, suplemento.

Sumario

1. Introducción.

2. Metodología.

3. Sobre la agenda setting del suplemento.

4. Sobre los públicos del suplemento.

5. Sobre la finalidad de los mensajes del

suplemento.

6. Conclusiones.

7. Referencias bibliográficas.

8. Notas

\section{Resumen}

Los suplementos informativos son uno de los recursos más explotados por parte de las instituciones para mantener contacto con el mundo exterior a través de la difusión de sus acciones más significativas. Con estos documentos se consigue, además, superar barreras comunicativas y mostrar transparencia externa. Suponen, pues, una herramienta muy útil a la hora de trabajar y mantener la imagen corporativa de la organización/institución y generar un clima positivo entre la totalidad de sus públicos. En este artículoi, pretendemos establecer cuál es el carácter y la tipología del suplemento "Paraninfo" que la Universidad de Alicante emite, semanalmente, en el Diario Información. A través del análisis de contenido, tratamos de definir los mensajes desde el punto de vista de su finalidad, su temática y el público al cual se dirigen para poder establecer cuáles son las premisas fundamentales que influyen en la configuración de la agenda setting de la Institución. Puesto que se trata de un análisis temporal que engloba los últimos cinco años de publicación periódica, permite establecer cuáles son los cambios significativos en la escala temporal y la evolución de su carácter. Además, permite valorar las tendencias generales en comunicación institucional y delimitar hacia dónde se dirige la comunicación de las organizaciones y, en concreto, de las Universidades pública.

\section{Forma de citar este artículo en las bibliografías}

Tatiana Hidalgo-Marí, Eliseo Rodríguez-Monteagudo (2013): “La tipología de los mensajes en el suplemento

"Paraninfo" de la Universidad de Alicante: temáticas, públicos objetivos y finalidad de los mensajes", en Miguel Hernández Communication Journal, nº , páginas 31 a 64. Universidad Miguel Hernández, UMH (Elche-Alicante).

Recuperado el__ de de 20

de: http: $/ /$ mhcj.es. $/$ index.php?journal $=$ mhcj\&page $=$ article\&op $=$ view\&path $\% 5 B \% 5 \mathrm{D}=3$ 


\title{
The types of messages in the supplement "Paraninfo" of the University of Alicante: themes, stakeholders and purpose of messages
}

\author{
MHCJ no 4 | Year 2013 \\ Paper no3 (41) \\ Pages 31 a 64 \\ mhcj.es
}

\author{
Doctora Tatiana Hidalgo-Marí | thm@alu.ua.es \\ Mgter. Eliseo Rodríguez-Monteagudo | erm10@alu.ua.es
}

Keywords

Institutional communication, media, content analysis, agenda setting, University of Alicante, supplement.

Sumary

1. Introduction.

2. Methodology.

3. About the agenda setting at the

supplement.

4. About the stakeholders of the

supplement.

5. About the prupose of messages of the

supplement.

6. Results.

7. Bibliographic reference.

8. Notes.

\begin{abstract}
Informative supplements are one of the most exploited resources used by the institutions to keep contact with the external world through the diffusion of their significant actions, so they can obviously overcome communication barriers and show external transparency. They are therefore supposed to be a very useful tool to run and maintain the corporate image of the organization / institution and create a positive atmosphere among all its stakeholders. In this article, we aim to establish which is the nature and the type of "Auditorium" the supplement weekly issued by the University of Alicante on the Informacion newspaper. Through content analysis, we try to define the messages from the point of view of its purpose, its theme and the public aimed to establish the fundamental premises that give influence on the configuration of the Institution's agenda setting. Since this is a temporal analysis including the last five years of regular publication, it enables to establish what the significant changes in the timescale and the evolution of his character are. It also allows an assessment on general trends in corporate communication and defines where the communication of the organization is addressed, especially at public universities.
\end{abstract}

\section{How to cite this paper in bibliographies}

Tatiana Hidalgo-Marí, Eliseo Rodríguez-Monteagudo (2013): “La tipología de los mensajes en el suplemento "Paraninfo" de la Universidad de Alicante: temáticas, públicos objetivos y finalidad de los mensajes”, en Miguel Hernández Communication Journal, n4, páginas 31 a 64. Universidad Miguel Hernández, UMH (Elche-Alicante). Recuperado el _ de de 20

de: http: $/ /$ mhcj.es. $/$ index.php?journal $=$ mhcj\&page $=$ article\&op $=$ view $\&$ path $\% 5 B \% 5 \mathrm{D}=3$ 


\section{Introducción}

Las universidades, centros del fervor del conocimiento, responden a una lógica organizativa que acerca el funcionamiento de las mismas a una estructura empresarial, jerárquica y configurada para responder a las demandas de un mercado muy heterogéneo. Estas empresas que acercan el saber al servicio público mantienen canales de comunicación con los públicos que, en algunos casos, no se adaptan a las necesidades del contexto sociotecnólogico y mucho menos a la demanda social de sus públicos. Sea como sea, las universidades, bien como instituciones públicas, bien como empresas generadoras de ciencia y cultural, necesitan tener una estrategia de comunicación muy definida y adaptada tanto al momento real en el que vivimos como a sus filosofías personales y sus intereses/objetivos empresariales.

En un contexto tecnológico implacable en el que las interacciones de base tecnológica ganan espacio en deriva a la comunicación interpersonal, resulta interesante plantearse de qué manera las universidades mantienen el contacto con sus públicos. La comunicación institucional, en general, y las propias universidades en particular, mantienen canales informativos tradicionales, que suponen una brecha en su estrategia comunicativa. Dicho de otro modo, a pesar de los avances y las inversiones millonarias para acercar la universidad al entorno digital 2.0 y 3.0 , los boletines informativos, tanto internos como generales o externos siguen siendo uno de los recursos más utilizados a la hora de establecer, mantener y difundir los mensajes de la institución.

Aunque la misión tradicional de las universidades se ha basado en dos líneas de actuación interconectadas, la docencia y la investigación, es evidente que si entendemos que estos centros del saber son instituciones que mueven no sólo el conocimiento sino una serie de beneficios y transacciones económicas importantes, también necesitan cuidar su imagen y su reputación, bien para demostrar transparencia y cercanía, o simplemente para mantener a los públicos vinculados a su filosofía, sus actividades y su crecimiento académico.

Además, la importante conciencia cultural que ejercen estas instituciones pone de manifiesto la necesidad imperante de mantener una comunicación directa y periódica con los públicos susceptibles de ser partícipes directos en los actos de la agenda. La Universidad del siglo XXI es más que el sumatorio de docencia e investigación puesto que se concibe como un seno en el que fluye la cultura, la socialización y la actividad divulgativa, un lugar de encuentro de académicos, artistas y profesionales en el que es necesario mantener una estrategia comunicativa que dote de fuerza al canal de comunicación.

Debemos tener en cuenta que cuando hablamos de actividad comunicativa no nos referimos solamente a los flujos de información que generan los mass media, sino que también entran en juego las actividades comunicativas o divulgativas de cualquier ente público o privado. Esta transmisión de información surgida de las organizaciones e instituciones es conocida como Comunicación Institucional y consiste en la manera en que las organizaciones públicas utilizan 
los recursos informativos como una expresión oficial ante la sociedad, a través de los medios de comunicación que tienen a su alcance. (García Rivas, 2003).

La universidad, como institución pública -en este caso- necesita a los medios para que su estrategia comunicativa sea directa y el alcance de la misma sea mucho mayor. La comunicación universitaria, que se define y perfila en sus propios gabinetes de prensa, agentes especializados y unidades comunicativas, vela por la integridad de la imagen de la propia universidad en tanto en cuanto pretende, en primer lugar, acercar la realidad universitaria a los públicos y, en segundo lugar, mantener la imagen transparente, actual y veraz del conglomerado institucional. En este sentido, podemos definir Comunicación Institucional como:

"Conjunto de relaciones que se extiende a todos los ámbitos de interacción organizacional y que se desarrolla como expresión oficial e intencional de la institución (...) a través de la integración de todos los medios a su alcance para facilitar su propio funcionamiento interno y favorecer la creación de una determinada imagen pública que permite la difusión de una personalidad de finida en congruencia con su propia realidad, sus expectativas y objetivos o percepciones de sus miembros y las demandas del entorno". (Losada Vázquez, 1998)

A esta definición de Comunicación Institucional debemos aplicarle el matiz del funcionamiento empresarial, teniendo en cuenta que los agentes partícipes en la organización política, económica y social de la universidad responden a una jerarquía similar a la de las corporaciones empresariales y, por tanto, no podemos obviar el interés económico/de beneficio que se transmite de éstas. Tal y como expone García Rivas (2003) citando a Sotelo Enríquez:

"La comunicación institucional (...) puede definirse como la función de marketing informativo, desarrollado por la institución, interna y extremadamente, con el fin de descubrir, configurar y difundir los principios de su identidad en el mercado de la información."

La Universidad de Alicante, como organismo dedicado al conocimiento y siguiendo una clara estrategia de comunicación -interna y externa- que busca mantener el contacto y la fidelidad de sus stakeholders, publica desde hace más de seis años, el suplemento Paraninfo en el Diario Información, medio impreso por excelencia en la provincia ${ }^{i i}$. Este suplemento es la publicación impresa más antigua, concisa y global de la Institución, ya que desde el 15 de noviembre de 2005 se encarga de difundir las actividades tanto investigadoras, docentes, culturales y/o de interés general para los públicos que con ella interactúan. 
Para entender la función e intencionalidad de los boletines/publicaciones institucionales es necesario entender que la universidad es un escenario social, cultural, político, ético-estético y cognitivo en el que se confrontan constantemente ideas, sentimientos y proyectos, pero sobre todo donde se viven y comparten experiencias, teorías y sensibilidades que pretenden ayudar a mantener, construir y desarrollar al individuo, la sociedad y la cultura (Murcia Peña, 2009: 244). En esta línea, Báez Padrón (2010: 348) identifica tres procesos en el desarrollo de las funciones y actividades de la universidad: el proceso docente-educativo, el proceso de investigación científica y el proceso de transferencia de los conocimientos a la sociedad. Tal y como explica Tonon (2012):

\begin{abstract}
"Tradicionalmente se ha venido desarrollando un esquema de trabajo universidad-sociedad que se ha basado primordialmente en la transferencia de conocimientos en un esquema de interacción con el medio circundante y si bien esta modalidad ha venido permitiendo un primer contacto y acercamiento al afuera de las instituciones universitarias, el desafío actual se centra en ampliar el trabajo en la construcción de relaciones universidad-comunidad que permitan efectivamente colocar el conocimiento generado por la universidad en respuesta a las necesidades sociales de la población."
\end{abstract}

En la actualidad, los medios instalan e imponen las noticias en la sociedad. Esta instalación e imposición de un temario en particular es lo que se conoce con el nombre de agenda setting. Los medios en general tienen diferentes formas de influenciar sobre la relevancia de determinados temas. De hecho, Wolf (1996: 167) aclara que:

"Los dos medios [refiriéndose a la televisión y el diario] están dotados de un diferente poder de influencia: las noticias televisivas son demasiado breves, rápidas, heterogéneas y están 'hacinadas' en un formato temporal limitado (...), al contrario, la información impresa posee todavía la capacidad de indicar eficazmente la distinta importancia de los problemas presentados".

En este contexto, aplicando las conclusiones de Wolf al ámbito del suplemento universitario podemos entender que la elección de la prensa como canal de comunicación por parte de la Universidad de Alicante responde a una lógica puramente marketiniana en tanto en cuanto pretende dotar a las noticias de un áurea propia de poder, es decir, dejar por escrito la realidad universitaria, poniendo de manifiesto su carácter actual, transparente y necesario en todo proceso de comunicación institucional.

Por su parte, Rodrigo Alsina (1996) afirma que: 
"La teoría de la construcción del temario apunta claramente que es muy posible que los mass-media no tengan el poder de transmitirle a la gente cómo deben pensar o actuar, pero lo que sí consiguen es imponer al público lo que han de pensar".

En este sentido, el hecho de que la Universidad difunda el suplemento informativo y supervise todo el proceso de comunicación no es un hecho banal, sino que se basa en la implantación de una estrategia a través de la cual la propia Institución manifiesta su necesidad patente de ser comunicada y ser entendida por los públicos, a saber, define de algún modo su filosofía y su personalidad a través del medio impreso, aunque esto se lleve a cabo siguiendo un patrón más aproximado a las lógicas comerciales que al propio fin informativo puro. Es necesario tener en cuenta que:

"La selección, tratamiento y presentación de los contenidos están marcados por estos criterios mercantiles, pero también por otros factores como las posiciones políticas, los poderes e ideologías que sustentan los propietarios de los medios, las estructuras de poder dentro de la organización y las relaciones de poder externas con otras organizaciones, es decir, con las fuentes y con los protagonistas de las noticias" (Van Dijk, 1990).

Así pues, la manera en que los temas e informaciones son tratadas en el suplemento en cuestión atienden directamente a una lógica social en la que la Universidad no sólo pretende fidelizar y mejorar las relaciones con sus públicos sino que además, establece y define una estrategia comunicativa que va más allá del propio proceso informativo y pretende orientar la opinión de los receptores, sus percepciones acerca de la Institución y su carácter sociopolítico y/o económico. (Van Dijk, 1990).

En las conclusiones que se presentan a continuación se pone de manifiesto cuál es la tendencia informativa en este proceso de comunicación así como la finalidad de los mismos y los públicos a los que se dirige, con la intención final de establecer unos parámetros acerca de la morfología del propio suplemento y sus principales características de contenido.

\section{Metodología}

La investigación planteada pretende aportar un estado de la cuestión a la publicación del suplemento semanal Paraninfo, atendiendo a la tipología de los mensajes, los públicos a los que se dirigen y la finalidad de los mismos. Para llevar a cabo este trabajo, nos servimos de una metodología cuantitativa a través de la cual podamos clasificar, tratar y valorar los datos específicos recogidos de la muestra. Este análisis cuantitativo se ha de basar en la realidad 
estadística de los propios datos para poder llevar a cabo una valoración basada en la cuantificación de los datos recogidos de la muestra.

El método a seguir para esta primera parte de análisis se centrará en la recogida de datos estadísticos, extraídos a partir de la muestra seleccionada y su clasificación cuantitativa, y desde unas variables predefinidas acordes con los objetivos de la investigación. Para ello se ha utilizado el soporte informáticos SPSS y el cruce de los datos obtenidos tras la recogida de información.

El método de trabajo se basa en la clasificación de cada una de las noticias/espacios publicados en el suplemento atendiendo a la temática de las mismas, el público al que se dirigen y la finalidad de los mensajes publicados. En la parte de discusión se pueden visualizar las variables de análisis que configuran cada una de las categorías analizadas y la justificación de las mismas.

No obstante, al tratarse de una investigación que pretende, entre otros objetivos, ofrecer una valoración y un estado de la cuestión sobre una publicación en concreto, es necesario tener en cuenta la presencia de ciertos recursos cualitativos que van más allá de la estadística pura y sirven como apoyo al trabajo cuantificado. Tendremos en cuenta las técnicas cualitativas a la hora de interpretar datos que, a pesar de estar basados en los resultados de la clasificación de las noticias analizadas, necesitará del juicio del propio investigador para llevar a cabo la interpretación final.

La muestra que apoyará esta investigación sobre el suplemento Paraninfo se constituye a partir de las noticias / espacios aparecidos en los últimos cinco años en el suplemento, es decir, desde 2007 hasta 2011. Esta selección es fruto del interés por mostrar, en primer lugar, una evolución temporal del carácter del suplemento y, en segundo lugar, por intentar acercar la realidad de la publicación a nuestros días y, valorar así, los cambios más significativos en la tendencia representativa de las noticias, la evolución de los públicos a quien se dirige y la finalidad de cada una de las inserciones. Debemos reclacar que el suplemento en cuestión se publica los martes de cada semana académica letiva, es decir, descartando las semanas que forman parte de vacaciones o puentes y descartando también los martes que supongan día no lectivo. Esta muestra nos permite acercarnos a la morfología del suplemento y pretende poner de manifiesto una tipología general que contribuya a la definición de la esencia del suplemento en cuestión.

\section{Sobre la agenda setting del suplemento:}

La Teoría de la Agenda Setting determina que los medios influyen en el público, directa o indirectamente, procurando la relevancia o el espacio informativo a temas o cuestiones que los medios eligen. El estudio realizado por McCombs y Shaw en 1972 establece que la gente considera unos temas más destacados (la agenda del público), que otros en proporción directa con la importancia que le den los medios (la agenda de los medios), aunque éstos no sean 
quienes decidan por la audiencia cual será la actitud o decisión de estos asuntos que proponen como agenda. "Su nombre metafórico proviene de la noción de que los mass media son capaces de transferir la relevancia de una noticia en su agenda a la de la sociedad" (McCombs, 1996:17). Según Noam Chomsky, la agenda-setting es:

"Una alianza tácita que existe entre el gobierno de un país (generalmente Occidental y sobre todo Estados Unidos) y los medios de comunicación para comunicar a los espectadores, oyentes o lectores de un determinado medio sólo lo que interesa, y ocultar al máximo lo que puede resultar peligroso o perjudicial para la estabilidad que ellos creen la correcta para su país".

Siguiendo las afirmaciones de Chomsky, podemos entender que cuando hablamos de agenda setting refiriéndonos a una institución -en este caso, a la Universidad de Alicante- hablamos implícitamente de los acuerdos de la propia Institución con el medio a través del cual difunden la información que consideran oportuna -en este caso, el Diario Información en concreto en el Suplemento Paraninfo-. Por tanto, nuestro estudio de clasificación de las noticias insertadas en dicho suplemento pretende aportar una visión empírica acerca de la aplicación de una agenda setting concreta, es decir, a qué noticias se les da más importancia, qué temáticas tienen más peso que otras y cómo esta tendencia en la generación de una tipología de noticias ha evolucionado o no a través de los últimos cinco años.

En palabras de Shaw, lo que la agenda-setting sostiene es que:

"Como consecuencia de la acción de los periódicos, de la televisión y de los demás medios de información, el público es consciente o ignora, presta atención o descuida, enfatiza o pasa por alto, elementos específicos de los escenarios públicos. La gente tiende a incluir o a excluir de sus propios conocimientos lo que los media incluyen o excluyen de su propio contenido. El público además tiende a asignar una importancia que refleja el énfasis atribuido por los mass-media a los acontecimientos, a los problemas, a las personas" (En Wolf, 1987:163).

Partiendo de la definición de agenda-setting que realiza Shaw, hay que reconocer que tiene razón en las dos características principales que destaca que son en primer lugar, que la gente sólo conoce lo que los mass media les ofrece, ignorando por completo cualquier otra noticia y, en segundo lugar que según los medios de comunicación den más importancia a una noticia o a otra, así lo hará también su público. (MCComb y Shaw, 1972)

Aplicando las estrategias básicas de comunicación al suplemento, podemos decir que se trata de una publicación institucional a través de la cual la cultura y los temas institucionales tienen 
mucho peso. Para clasificar las principales temáticas que se detectan hemos establecido las siguientes categorías:

- Institucional: en esta categoría tienen cabida todas las noticias que re refieren a la Universidad como Institución, refiriéndose a la naturaleza de la misma, su carácter político y/o económico y su organización.

- Alumnado: recoge cada una de las inserciones que hacen referencia a los alumnos como públicos internos de la propia Universidad, bien poniendo de manifiesto sus logros, proyectos, participaciones, inquietudes, etc.

- Centros y departamentos: incluye las noticias que se emiten desde los centros universitarios, bien facultades, escuelas, institutos de investigación, departamentos u otros centros adscritos a la Universidad.

- Deporte: recopila todas las noticias que hacen alusión a los logros, proyectos o estado de la situación de la Universidad, sus equipos y deportistas, instalaciones, proyectos, eventos programados, etc.

- Cultura: engloba las noticias cuya temática pretende informar, recordar, mostrar o dejar constancia de las distintas actividades culturales de la Universidad, bien organizadas por el propio secretariado de cultura, bien surgidas de las sedes o entes privados.

- Divulgación: son noticias que pretenden dar a conocer el estado de la ciencia, los logros y avances científicos de la Universidad o bien recoger un tema científico para hacerlo llegar a los públicos.

- Publicitaria: hace referencia al carácter comercial de la información, bien sea a través de anuncio publicitario, bien a través de noticias que promulguen o den pie a la actividad comercial de cualquier bien o servicio. No obstante, y sin ánimo de avanzar las conclusiones del análisis, procedemos a exponer los resultados de la investigación.

- Otras: las noticias de esta categoría son aquellas que por su naturaleza se alejan de una posible clasificación basada en las categorías anteriores. Se trata de una temática en la que hemos incluido tipos de noticias de difícil clasificación.

Una vez expuestas y definidas las categorías de análisis sobre los diversos temas, hemos obtenido los datos que exponemos a continuación y que se muestran, por una parte bajo la cuantificación de los mismos y, en segundo lugar, con un análisis cualitativo que interpreta la totalidad de datos obtenidos. Después de haber registrado, clasificado y analizado todas y cada 
una de las noticias aparecidas en el suplemento Paraninfo, desde el año 2007 hasta el año 2011, podemos establecer una comparativa respecto a los temas que ocupan este boletín comunicativo de la Universidad de Alicante.

La metodología llevada a cabo nos permite clasificar cada una de las noticias que aparecen en ocho categorías distintas (noticias institucionales, noticias referidas a alumnado, noticias referentes a Centros y Departamentos, noticias deportivas, culturales, de divulgación y publicitarias). Además se añade una característica denominada "otros" en la que tenemos en cuenta noticias que se alejan de las temáticas predefinidas. El resultado porcentual que corresponde a cada una de las categorías establecidas se puede contemplar en los gráficos siguientes:

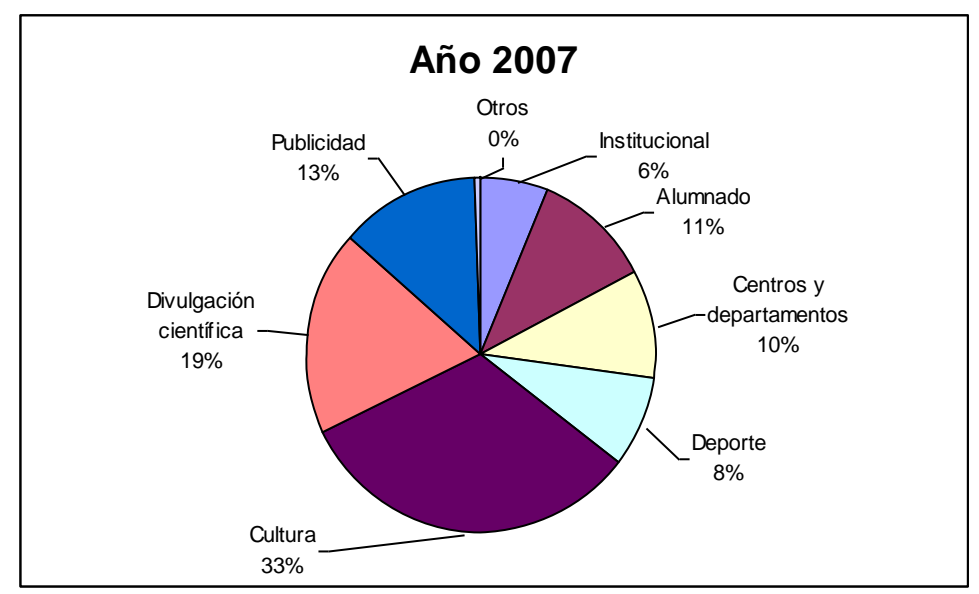

Imagen 1: temáticas año 2007.

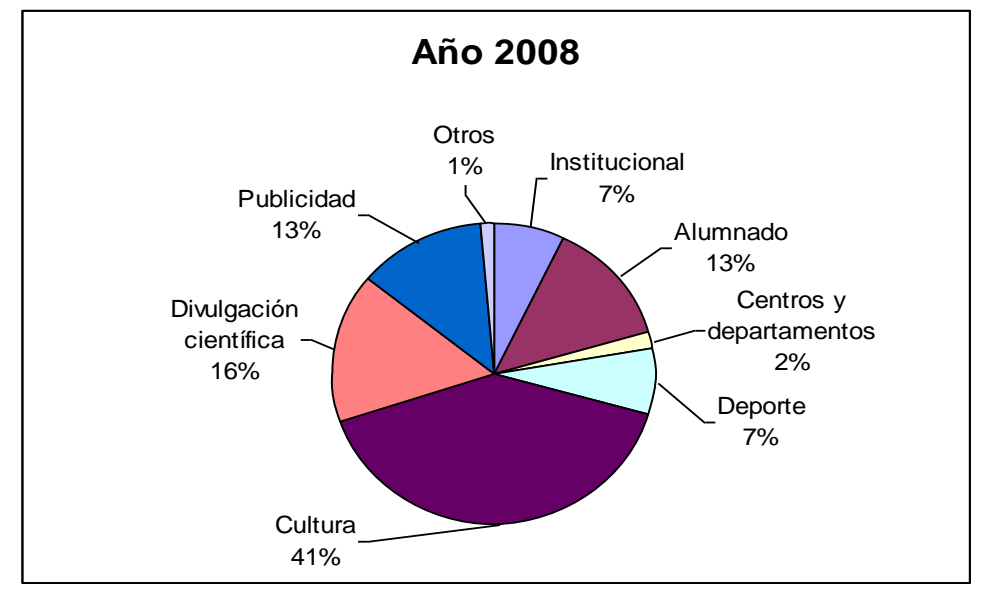

Imagen 2: temáticas año 2008. 


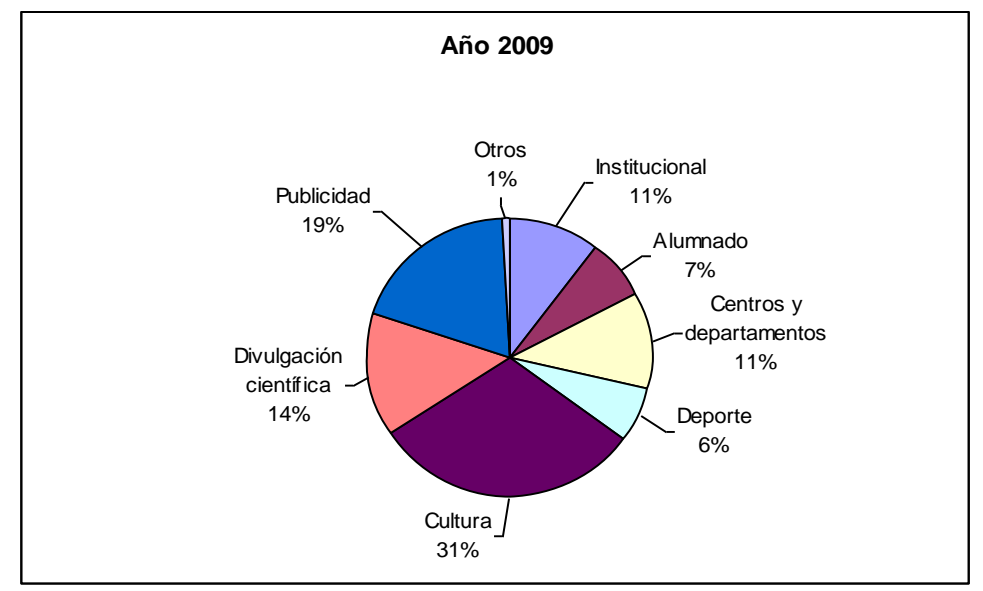

Imagen 3: temáticas año 2009.

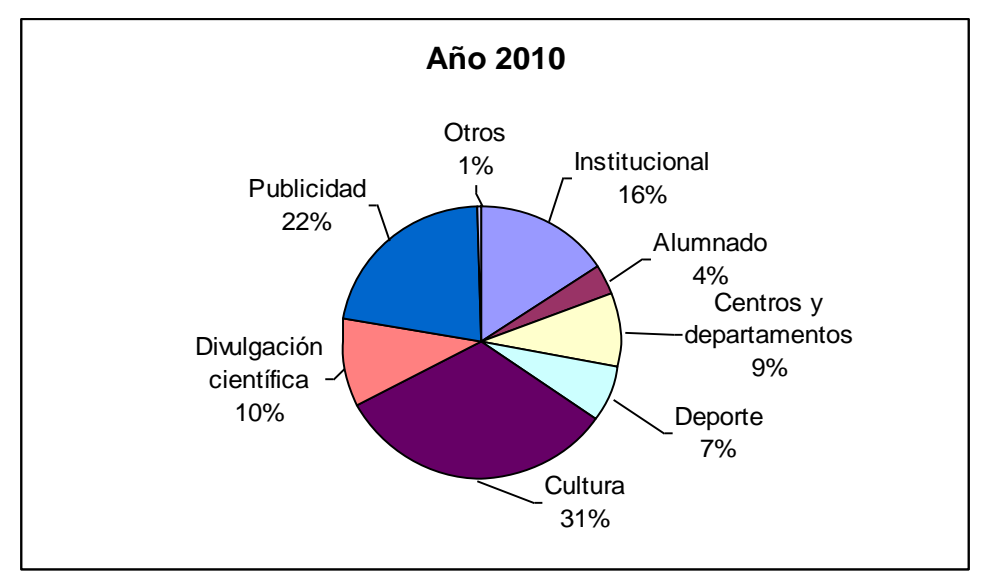

Imagen 4: temáticas año 2010.

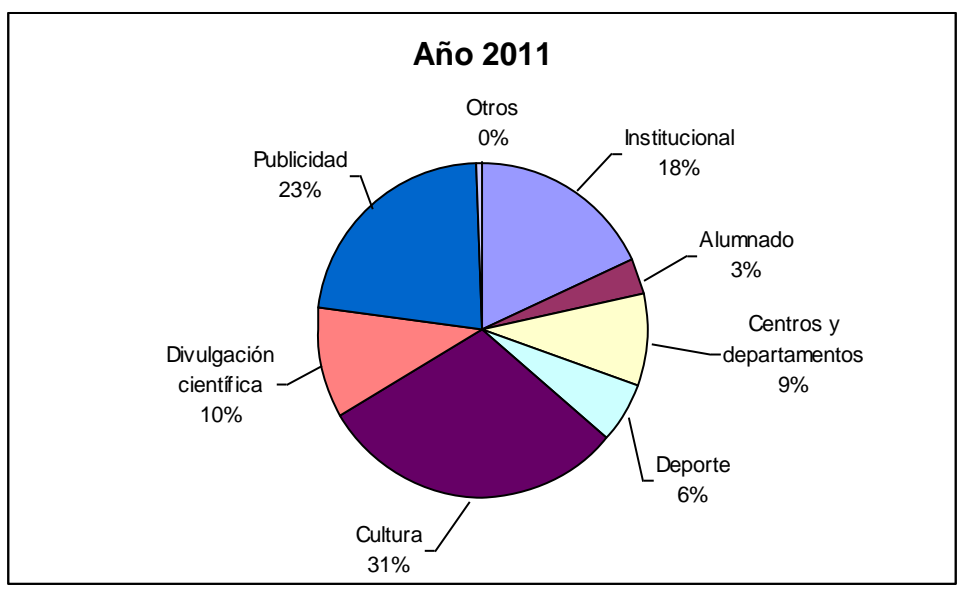

Imagen 5: temáticas año 2011. 


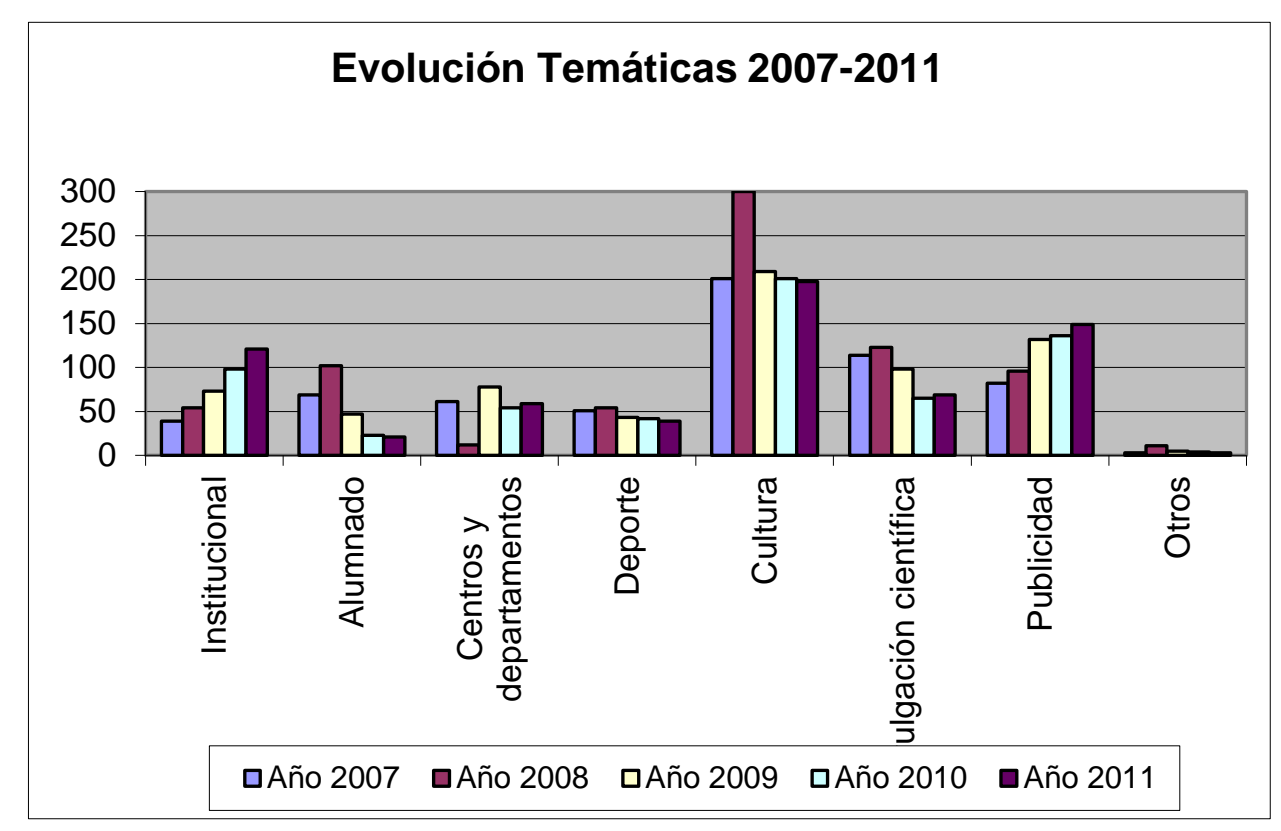

Imagen 6: Evolución temáticas 2007-2011

Una vez realizada la clasificación inicial de las temáticas que caracterizan a cada una de las noticias aparecidas en el Suplemento Paraninfo del Diario Información de Alicante, pretendemos ponerlas en relación para poder valorar en su caso, tendencias, cambios o similitudes entre los años analizados y, al mismo tiempo, valorar la evolución en la manifestación de las mismas.

Tal y como podemos comprobar en el gráfico anterior (imagen 6), existe cierta tendencia normalizadora en cuanto al uso de la agenda setting en el suplemento. Esto es, que existe una apreciable homogenización de los temas que componen las noticias y la importancia que se les da a los mismos.

Si hablamos de las noticias cuyos temas hacen referencia a la Institución en sí, observamos una clara tendencia creciente desde el año 2007 hasta el 2011. En el primer año analizado observamos que el porcentaje dedicado a las noticias de carácter institucional era del $6 \%$ mientras que en los años posteriores la tendencia es creciente, situándose en un $7 \%$ el año 2008, un $11 \%$ en 2009, un 16\% en 2010 y, finalmente, un $18 \%$ en 2011.

Contemplamos, por tanto, que desde la Institución se pretende subrayar la imagen de la propia organización, dotando de cada vez mayor importancia a las noticias propias o autoreferenciales. Aunque el aumento supone sólo un $12 \%$, es interesante tenerlo en cuenta puesto que refleja claramente la intencionalidad de la agenda setting del suplemento, que en los últimos cinco años ha detectado la necesidad de proteger, cuidar y mantener la imagen de la Institución y para ello, aumentan progresivamente la cantidad de noticias autoreferenciales, bien sea para contribuir a la imagen positiva de la organización, bien para mostrarse como una 
institución transparente y clara que, cada vez más, comunica y incluye en su línea de comunicación las noticias propias de la organización universitaria.

Estos hechos nos confirman que desde la propia Universidad se tiene en cuenta la importancia de la imagen en el mercado global y, por tanto, se pretende favorecer tanto el posicionamiento de la marca de la Universidad de Alicante entre su público como potenciar su valor activo intangible para aumentar así su importancia socioeconómica.

Por otro lado las noticias que hacen referencia al alumnado, bien sean sobre actividades desarrolladas por los mismos, sobre sus propios logros o sobre acciones complementarias en las que los alumnos son protagonistas, pierden presencia en el suplemento con el paso de los años. Al principio del análisis, en el año 2007, las noticias que hacían referencia a los alumnos suponían un $11 \%$ del total de noticias aparecidas en el suplemento. No obstante, y después de un crecimiento parcial en el año 2008 en el que representaban un 13\% del total, fueron descendiendo progresivamente situándose en un 7\% el año 2009, un 4\% el año 2010 y, finalmente un 3\% en el último año de análisis.

Esta tendencia decreciente en la importancia del alumnado en la temática general del suplemento explica que, de algún modo, la Institución empieza a utilizar el suplemento informativo como una herramienta de comunicación de marketing, es decir, dando cada vez mas importancia a los temas institucionales y reduciendo considerablemente la importancia de sus públicos internos en la configuración de la agenda setting. Dicho de otro modo, los datos del análisis demuestran que la importancia que en un principio se le dio a los temas relacionados con los alumnos decaen progresivamente a partir de 2008 para dar lugar a noticias cada vez más institucionales, en las que la organización es la protagonista.

En cuanto a las noticias que hacen referencia a los Centros y Departamentos de la propia Universidad y que hablan de actividades, logros y proyectos de éstos, destacamos una tendencia equilibrada en la representación de los mismos. A pesar de que existe un descenso muy pronunciado en el año 2008 (en este año sólo detectamos un 2\% de noticias de esta procedencia, en contraposición al 10\% del año anterior), el porcentaje de noticias que configura esta categoría oscila entre el 9 y el 11\%.

Podemos entender que el descenso prolongado de esta temática en el año 2008 deriva de la importancia creciente de la temática "alumnado" en el mismo año. A pesar de ello, podemos decir que la importancia que se le da a las noticias vinculadas con los Centros y Departamentos universitarios (entendamos también facultades, escuelas, Institutos de investigación....) supone una categoría poco relevante en la estrategia temática del suplemento y se utiliza, generalmente, para completar otros temas más importantes en esta estrategia divulgativa, a saber, alumnado, institucional o cultura. 
La categoría dedicada al deporte se mantiene en un intervalo de representación constante, que oscila entre el 8\%en el año 2007, el 7\% en 2008, un 6\% en 2009, un 7\% en 2010 y, finalmente, se asienta con un $6 \%$ en 2011 . Vemos que se trata de una categoría bastante consolidada en el suplemento, pues a lo largo de los años, el espacio dedicado a las noticias de este tipo es similar, sin grandes cambios. Cabe decir que las noticias de deportes gozan de una sección propia en el suplemento, que se mantienen a través de los cinco años de análisis. Por este motivo, afirmamos que el deporte supone una vía de comunicación muy presente para la Institución, ya que no ve afectada significativamente su presencia en los cinco años analizados. Así pues, se trata de una categoría que se mantiene estable con el paso de los años, aferrada a la estrategia temática de la Institución pero que, a pesar de ello, sufre un ligero descenso gradual en los últimos años.

La temática vinculada a la cultura es, probablemente, el tema al que más importancia le dedica la Institución. A pesar de que nos encontramos ante un suplemento informativo de la propia Universidad y, por tanto, debemos diferenciarlo de un suplemento cultural, no podemos obviar el peso que tiene el tema cultural en esta herramienta comunicativa. Con diferencias, los temas culturales ocupan grandes porcentajes en la distribución de noticias, siendo, por ejemplo, de un $33 \%$ en 2007 , un $41 \%$ en 2008 , un $31 \%$ en 2009,2010 y 2011 . Observamos que se trata de un porcentaje mucho mayor al que ocupan otros temas en la agenda setting del suplemento. Además, se trata de un tema muy consolidado en la estratega comunicativa ya que -al margen de una subida considerable en 2008, en el que representa el $41 \%$ del total de las noticias emitidas-, se mantiene estable alrededor del 30\% en los años analizados. Vemos, pues, que el equilibrio en el porcentaje dedicado a cada temática nos confirma la consolidación de una temática en concreto, a saber, de la cultura, como una de las vías de comunicación más importantes en el suplemento analizado.

Sorprende que los temas dedicados a la divulgación científica y la comunicación de la ciencia, bien sea de logros y avances de la Universidad en el campo científico, bien a través de la divulgación convencional y cotidiana de la ciencia no adquieren un peso sustancial en la totalidad de la publicación. Según los datos recogidos en nuestro estudio, las noticias relacionadas con la divulgación disminuyen con el paso de los años y cada vez su tendencia es más decreciente. En el año 2007, por ejemplo, las noticias relacionadas con la ciencia ocupaban el 19\% del total de noticias emitidas y se muestran en decadencia, ocupando un $16 \%$ en el año 2008, un 14\% en 2009 y tan sólo un 10\% en los años 2010 y 2011.

Resulta curioso como en un momento en el que la divulgación científica se encuentra en pleno auge, tanto a nivel académico como social, la Universidad, como institución volcada con el conocimiento, el saber y la investigación no mantiene una estrategia sólida en la comunicación de la ciencia -tanto la propia como la general- además, no sólo sorprende el relativamente poco espacio que se dedica a estos temas sino que también llama la atención el constante decrecimiento que sufre esta categoría. Por tanto, podemos observar que la comunicación 
científica no ocupa un lugar prioritario en la agenda setting de la Institución y mucho menos se presenta como una categoría temática sólida, ya que su peso, que no es excesivo en el suplemento, cada vez es menor.

La publicidad, bien a través de anuncios propios o bien a través de publireportajes o noticias comerciales, se muestra en constante crecimiento. Se trata de una categoría que, al principio del análisis ocupa solamente un 13\% del total de las noticias, representando un 13\% en 2007. Pero, con la evolución temporal, las noticias comerciales y la propia publicidad de la Universidad ocupan cada vez más espacio en el seno de la publicación, representando un 13\% también del total en 2008, un 19\% en 2009, un 22\% en 2010 y llegando a representar el 23\% del total del suplemento en 2011. Observamos, pues, que la estrategia comunicativa de la Institución no descarta la información comercial como uno de los temas recurrentes en su agenda. La autopublicidad, por una parte, y las noticias comerciales, por otra, se muestran como una categoría consolidada y con una presencia estable, en constante crecimiento en la planificación temática del suplemento.

La categoría otros resulta prácticamente insignificante en el seno de la configuración de la agenda setting de la publicación, ya que en ningún caso ocupa más del 1\%. Se trata de una categoría "cajón de sastre" en la que podemos encontrar alguna noticia que se aleja de las temáticas establecidas a priori. Observamos que su carácter equilibrado y constante confirma que se trata de una categoría sin relevancia, en primer lugar, porque ocupa muy poco espacio en la tendencia general y, en segundo lugar, porque no presenta altibajos en su clasificación, hecho por el cual podemos afirmar que la Universidad se aleja de temas que no estén directamente vinculados a las categorías establecidas y rechaza de su planificación temática cualquier noticia que no pueda ser clasificada como institucional, de alumnado, de centros y departamentos, de deporte, cultural, de divulgación científica o publicitaria.

\section{Sobre los públicos del suplemento}

En un contexto de constante cambio, la comunicación es una herramienta fundamental para establecer la estrategia de una institución / organización ya que, entre otras cosas, a través de ella, se da a conocer la multidisciplinar actividad universitaria y se pone de manifiesto el carácter innovador y actualizado de la misma. Además hablando de universidades como centros de fervor del conocimiento y teniendo en cuenta que la comunicación es una disciplina académica más, es necesario un flujo entre una y otra que permita que la universidad se perciba por sus públicos como una institución moderna, adaptada al cambio y en constante reinvención.

La configuración de los temas, de una manera estudiada y con una estrategia basada en los intereses de la institución -es decir, la agenda setting- no puede entenderse sin un público receptor de esos mensajes. Al contrario, la configuración de una agenda temática en la que se prioriza sobre unos temas frente a otros necesita, inexorablemente, de una concienciación 
acerca de los públicos, una mirada a la recepción de los mensajes, en definitiva, un mapa en el que se tengan en cuenta los receptores como agentes implicados directamente en el proceso de comunicación. (McCombs, 1994; Rodríguez Díaz, 2004).

En los estudios recientes que tratan la comunicación universitaria, se habla de una política universitaria que no se limite a la visión de la eficiencia educativa y de las operaciones sino que vaya más allá y que considere a los diferentes stakeholders de la institución para plantear una visión holística del proceso educativo (Reavill, 1998).

Dicho de otro modo, la holística es necesaria en el planteamiento de las estrategias comunicativas universitarias, puesto que a través de ella conseguimos entender el sistema universitario no sólo como la suma de sus partes integrantes sino como un conglomerado de interacción dinámico, en el que las relaciones entre públicos son constantes y contribuyen al desarrollo del propio sistema.

Para Freeman (1984) los públicos son: "Aquellos grupos o individuos que pueden verse afectados por los logros de los objetivos de la organización”. Otros hablan de los públicos de la universidad como:

\begin{abstract}
"Diversos actores sociales, tanto internos (integrantes de la comunidad universitaria y agrupados en general bajo las categorías de estudiantes, personal docente e investigador y personal de administración y servicios) como externos a la institución (otras administraciones públicas, entorno económico, educativo y cultural, antiguos y futuros alumnos, etc.)" (De Aguilera Moyano, et.al., 2008:94)
\end{abstract}

De todos modos, el planteamiento acerca de los públicos en las organizaciones ha generado, desde hace años, un extenso debate que radica en la clasificación de los mismos y el intento de categorizarlos (Friedman y Miles, 2006; Wolfe y Putler, 2002). Otros autores hablan de la necesidad de equilibrar los públicos de la organización para lograr la efectividad de la organización. (Anderson, 1982) Si aplicamos estos planteamientos al entorno universitario debemos validar su alcance, teniendo en cuenta que nos alejamos del sistema privado. (Reavill, 1998).

Existen muchos modelos de stakeholders, entre los que podríamos destacar el modelo de Freeman (1984) por tratarse de un modelo gráfico y haberse convertido en el parámetro de representación visual básico en este contexto. No obstante, con la intención de acercar los públicos a nuestro ámbito de estudio, debemos citar de nuevo a Reavill (1998) y su clasificación de públicos universitarios que se basa en la siguiente clasificación: 1) Estudiantes; 2) Empleados; 3) Familia y dependientes del estudiante; 4) Universidades y sus empleados 5) Proveedores de bienes y servicios 6) Sector de educación secundaria 7) Otras universidades; 8) El comercio y la industria 9) La nación 10) El gobierno 11) Los contribuyentes locales y nacionales y 12) Los cuerpos profesionales. 
Sea como sea, y sin intención de desarrollar un debate sobre los públicos de la institución y sus funciones o grados de implicación, hemos establecido cuatro categorías de análisis que responden a las lógicas citadas anteriormente pero que pretender sintetizar los stakeholders de la Universidad de manera que sea más conciso detectar a qué agentes sociales se dirigen los mensajes emitidos por la misma y difundidos a través del suplemento Paraninfo. Así pues, en nuestro análisis hemos establecidos las siguientes categorías:

- Públicos Internos: entenderemos por públicos internos aquellos públicos que configuran la comunidad universitaria directamente, es decir: estudiantes (de grado, postgrado o otras formaciones), personal docente e investigador (sea cual sea su condición o grado) y personal de administración y servicios (en todas sus variantes). Estos públicos suponen la vinculación más directa con la Institución puesto que conviven en tiempo y espacio con la misma y de los depende tanto en funcionamiento lógico general de la Universidad como la imagen transmitida de la misma.

- Públicos Externos / Generales: entendemos por públicos externos o generales aquellos que se alejan de la comunidad universitaria, no tienen ningún tipo de relación académica o contractual y no suponen un vínculo en ningún aspecto con la misma. Se trata de la categoría menos influyente en la comunidad universitaria ya que no existe vinculación con la misma. Deduciremos que los mensajes que se dirigen a públicos externos son, a su vez, mensajes generales de interés público, ya sean temas institucionales como culturales, publicitarios o de divulgación.

- Públicos Vinculados: entendemos por públicos vinculados aquellos que se caracterizan por no formar parte de la comunidad universitaria pero que mantienen cierto vínculo de relación con la misma. Se trata de un tipo de público externo que muestra cierta relación directa con la Institución a pesar de no formar parte de ella. En esta categoría podemos destacar desde futuros alumnos, otras universidades, padres/tutores de alumnos, profesionales de otras universidades, grupos políticos, órganos gubernamentales, asociaciones culturales, empresas, compañías de servicios, ...... .

Esta clasificación divide en dos la categoría de públicos externos promulgada por De Aguilera Moyano (2008) obteniendo una categoría de públicos externos y otra de públicos vinculados, ya que consideramos que existe cierta diferencia entre estos públicos y que los mensajes institucionales, en este caso, los de la propia Universidad de Alicante, tienen en cuenta estas diferenciaciones a la hora de establecer los públicos de sus mensajes. Además, supone una agrupación global de los públicos caracterizados por Reavill (1998), ya que la categoría de públicos internos incluiría las categorías de estudiantes, empleados y personal de la Universidad en general (categorías 1, 2 y 4 de Reavill); los externos agrupan las categorías de el comercio y la industria, nación, gobierno, los contribuyentes locales y nacionales y cuerpos profesionales (categorías 8, 9, 10, 11 y 12 expuestas por Reavill) y los públicos vinculados se encargan de 
englobar las categorías de familia y dependientes, proveedores, sector vinculado de la educación y otras universidades (sectores 3,5,6 y 7 estipulados por Reavill).

El interés por el estudio de los públicos a los que se dirige la Institución en sus mensajes en el suplemento surge de la necesidad de tener en cuenta a quién van a llegar los mensajes y, más aún, a quien se quiere que lleguen. Es decir, el suplemento Paraninfo, como herramienta de comunicación que acompaña al periódico Información tienen un alcance, a priori, similar o igual al de los propios lectores del periódico (un grupo amplio y heterogéneo pero con unos rasgos sociodemográficos predominantes que conforman un perfil interesante y estratégico para la Universidad). No obstante, cada una de las noticias que configuran el suplemento tiene un claro destinatario final, sobre el cual pretende influir o afectar de laguna manera, despertando su interés, haciéndolo sentir partícipe o, simplemente, acercándole información.

En el contexto de la agenda setting y la deliberación de los temas que ocupan el suplemento universitario es necesario plantearse quien será el destinatario final, pues de esta manera se asegura una correcta aplicación de los patrones estratégicos de la propia agenda, además de entender la universidad como un sistema holístico en el que todos los agentes juegan un papel importante tanto en la configuración de la imagen corporativa/institucional como en el desarrollo pleno de la estrategia de comunicación (Reavill, 1998). Alejados de aquellos tiempos en los que la comunicación era unidireccional, en estos momentos el lector es un sujeto partícipe del proceso, es decir, tiene capacidad de respuesta, directa o indirecta, a los mensajes de la Institución y puede influir directamente tanto en la creación de noticias de interés como en la divulgación de las mismas.

Es por este motivo que el conocer los públicos en el encuadre de la agenda setting adquiere cada vez más importancia. Además, el estudio y conocimiento de los públicos a quien se dirigen los mensajes institucionales nos permitirá establecer cuál es la estrategia final del suplemento, es decir, no sólo conocer las intenciones surgidas de la planificación de temáticas a difundir, sino también saber a quién se dirigen esas temáticas, quién es el receptor esperado y, por consiguiente, a quién se pretende llegar, de qué modo se quiere hacer y cuál es el objetivo final de esta estrategia comunicativa.

Centrándonos en el análisis de los públicos a quien se dirigen las noticias /mensajes que la Institución difunde a través del suplemento, observamos que existe una clara tendencia a dirigir los mensajes al público en general, entendiendo que estos engloban los públicos internos, los vinculados y la sociedad global. Según podemos observar en los diagramas de sectores siguientes (imagen 7, 8, 9, 10 y 11), los datos registrados nos muestran un claro equilibrio en los mensajes que se difunden dirigidos al público general. Exceptuando un considerable descenso en el año 2008, en el que los mensajes para públicos generales no superaron el $9 \%$, podemos afirmar que los mensajes destinados a la sociedad en general suelen ocupar alrededor de casi el 50\% de los mensajes emitidos en el suplemento. 


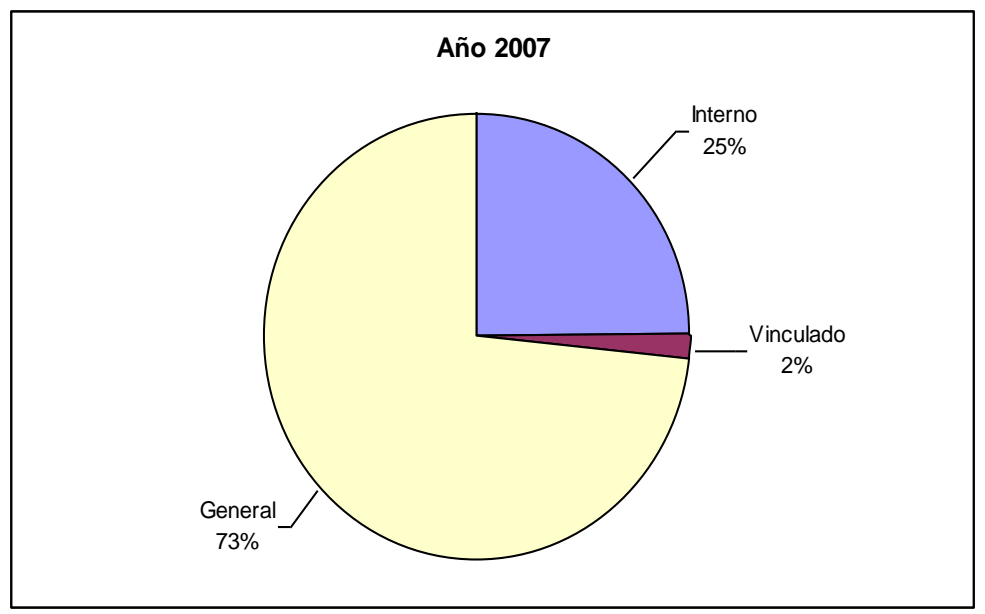

Imagen 7: Distribución públicos Año 2007

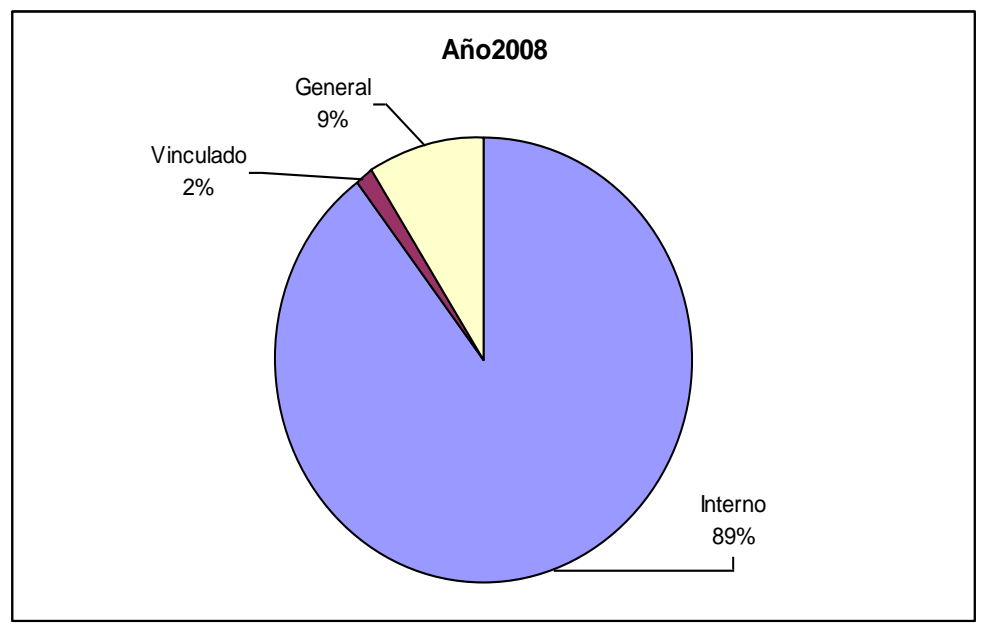

Imagen 8: Distribución públicos Año 2008 


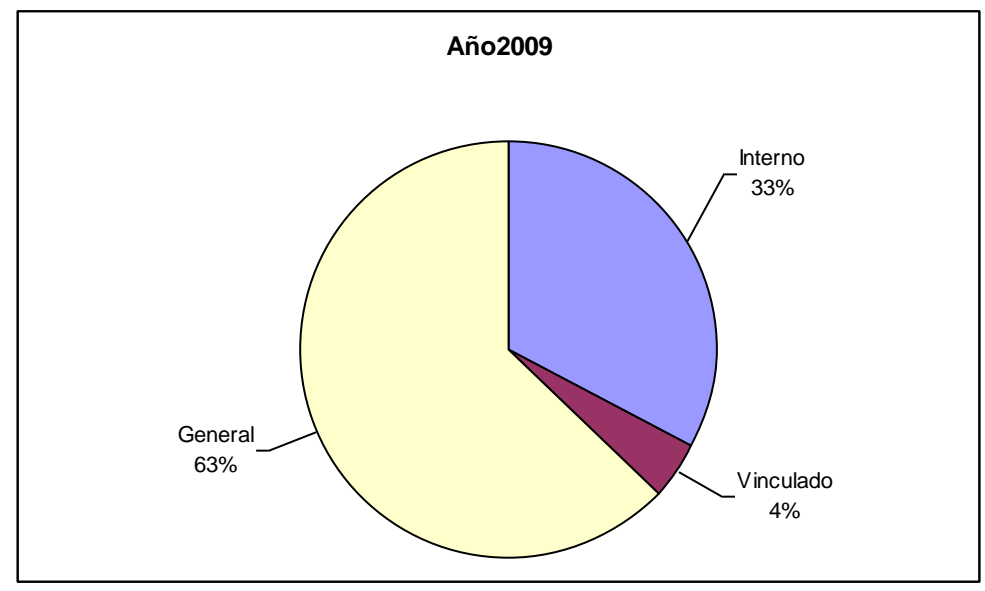

Imagen 9: Distribución públicos Año 2009

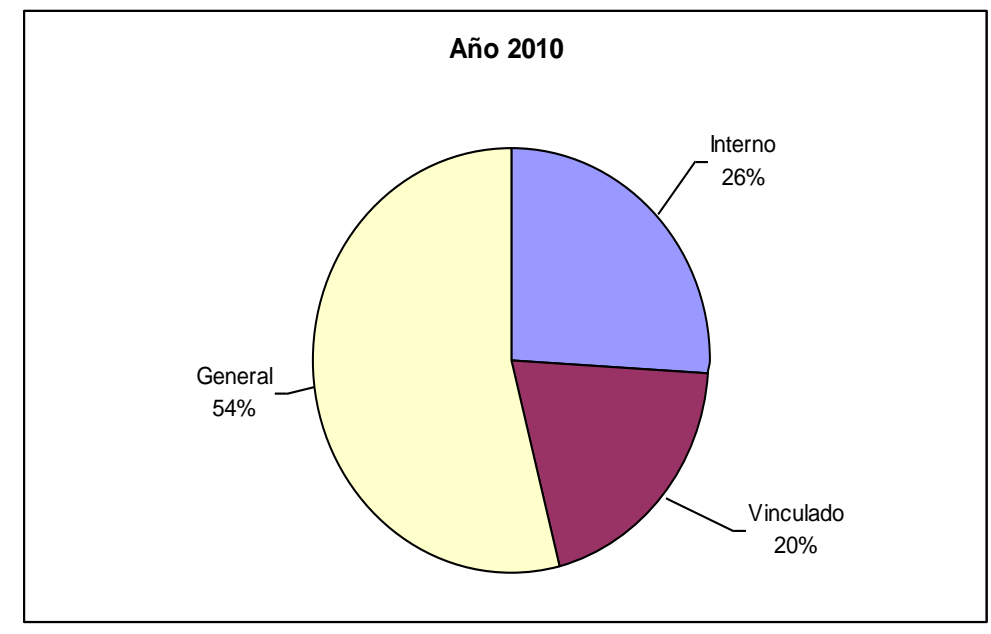

Imagen 10: Distribución públicos Año 2010

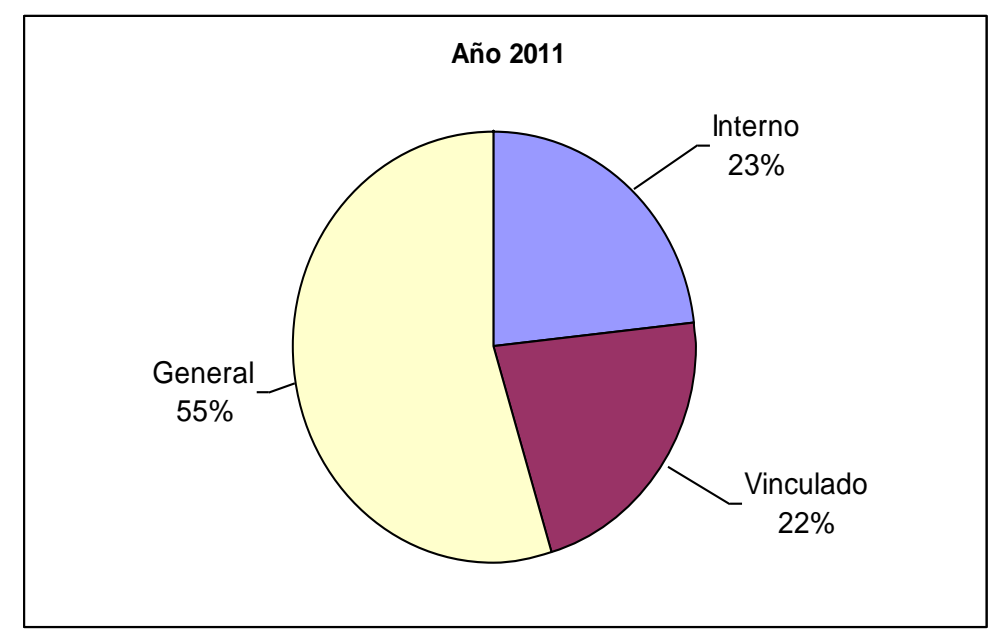

Imagen 11: Distribución públicos Año 2011 


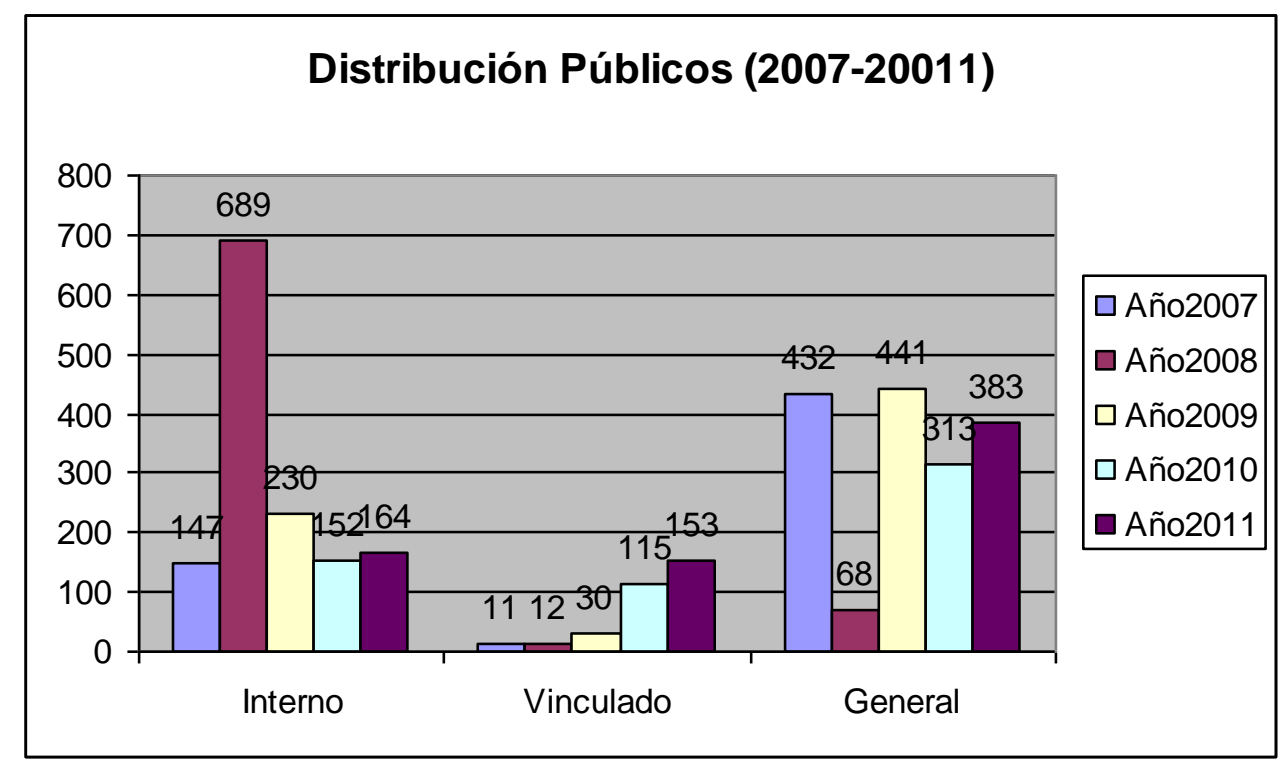

Imagen 12: Evolución en la distribución de públicos (Año 2007-2011)

En cuanto a los mensajes que se dirigen a los públicos en general, observamos una tendencia estándar que se sitúa entre el 73\% el año 2007, un 63\% el 2009, un 54\% en 2010 y un 55\% en 2011. Cabe destacar la creciente subida de los mensajes dirigidos a los públicos internos en el año 2008, que alberga el 89\% del total de los mensajes. Este dato creciente y destacable coincide en tiempo con el descenso de los mensajes dirigidos al público en general, hecho que nos permite afirmar que en este año hubo un claro interés en dedicar la información del suplemento universitario a sus públicos internos (alumnado, personal de administración y servicios y personal docente e investigador.) $)^{i i i}$.

Los públicos vinculados, en principio, no representan un objetivo importante en la delimitación de los receptores de los mensajes. Al contrario, observamos que sólo un 2\% de los mensajes emitidos en 2007 iba dirigido a este colectivo que engloba a públicos externos a la comunidad universitaria pero influyentes en la misma y relacionados de algún modo, con los públicos internos. A pesar de que los datos en principio son muy bajos, no podemos pasar por alto que se trata de una categoría de públicos en constante crecimiento, pues, como se observa en el gráfico global (imagen 12), los mensajes dirigidos a los públicos vinculados crecen progresivamente cada año, situándose en un $2 \%$ también en 2008, pero creciendo hasta un $4 \%$ en 2009 , y un 20 y $22 \%$ en 2010 y 2011, respectivamente.

Puesto que los mensajes del suplemento se dirigen mayoritariamente a un público general, podemos afirmar que una de las finalidades de la publicación recae en hacer llegar la realidad universitaria a la sociedad externa a la misma. Es decir, la Universidad, como institución pública y, a su vez, como conglomerado que sigue una lógica empresarial, necesita divulgar su actividad con la intención, en primer lugar, de reflejar transparencia en la gestión y accesibilidad a la sociedad en general y, en segundo lugar, para poder ampliar sus públicos internos, es decir, 
generar un marco informativo de sus actividades que acerque la universidad a la sociedad y que, además, mantenga un vínculo con los públicos externos. Además, si tenemos en cuenta que la Universidad ha seleccionado un medio local escrito, cuyo alcance es notable en la provincia de Alicante ${ }^{i v}$, podemos afirmar que su estrategia comunicativa va más allá de la mera interconexión y contacto con sus públicos internos y que pretende ampliar su alcance y su presencia informativa haciéndola extensible al seno de la población más cercana territorialmente.

A pesar de eso, no podemos obviar que los mensajes que se dirigen a los públicos internos tienen cierta importancia en la configuración de la estrategia comunicativa. Exceptuando el año 2008 que, como hemos comentado, es año de elecciones y por tanto se busca el respaldo y la cooperación de la comunidad universitaria, el resto de años presentan datos relativamente equilibrados. Esto nos permite pensar que, a pesar que los objetivos de la Universidad van más allá de la propia comunidad universitaria, en todo momento esta presente ésta en la definición de la estrategia de comunicación, ya que a través de esta herramienta se puede, en primer lugar, mantener informado al público interno y, en segundo lugar, generar vínculos fuertes y cercanos, lazos de cooperación y cercanía entre la propia Universidad y los públicos que la configuran. Esta importancia de los públicos internos en la divulgación de los mensajes responde a las necesidades holisticas de las que nos hablaba Reale (1998).

La Universidad no puede entenderse como una institución fría, sobria y cerrada; hay que romper la barrera estructurada unidireccional y mostrarse como un sistema organizacional en el que todos y cada uno de los agentes que la configuran sean actores partícipes de la actividad de la misma. Se trata, por tanto, de la manifestación del dinamismo y la entre los stakeholders, para interactuar y establecer vínculos que muestren a cada uno de los integrantes de la comunidad universitaria como agentes susceptibles de formar parte de su funcionamiento y su lógica organizacional. Vemos, pues, que la importancia de comunicarse con los públicos internos, al margen de suponer una estrategia de relaciones públicas internas necesaria, contribuye a la armonía de la propia organización y fomenta el dinamismo entre sus componentes (Reale, 1998).

Debemos hacer hincapié en la creciente importancia de los públicos vinculados a la hora de establecer los mensajes. Observamos que esta categoría representa un porcentaje muy bajo en relación a las otras dos mencionadas. Solo un 2\% en 2007 y 2008, un 4\% en 2009 pero llegando a un 20 y un $22 \%$ en los años 2010 y 2011. Estos datos, a pesar de mostrar una categoría que no afecta demasiado a la estrategia comunicativa de la Institución, se muestra en constante crecimiento -pequeño, pero constante-. Este dato permite entender que la Universidad cada vez es más consciente de la necesidad de establecer una estrategia comunicativa que abrace a todos los agentes influyentes en la misma y que permita la integración de todos los stakeholders relacionados y que permita que el avance de la Institución no sea arbitrario, sino que suponga una cooperación entre todos los grupos de interacción. 
La Universidad, por tanto, consciente de los cambios contextuales, integra progresivamente a sus públicos vinculados en los mensajes, para hacerlos participes del proyecto público y global y, además, acentuar su imagen positiva tanto entre los públicos internos como en los generales. Podemos decir, además, que el lento pero creciente interés por los agentes vinculados representa, de alguna manera, la globalidad de la Institución, ya que con el fortalecimiento de la comunicación con estos públicos vinculados se solidifica la comunicación con los internos y generales, esto es, se generan relaciones fuertes tanto de influencia como de aceptación y, por tanto, el proceso de comunicación global se ve aprecia como más sólido, accesible y transparente.

\section{Sobre la finalidad de los mensajes}

Hablar de la finalidad de los mensajes, en el seno de la Teoría de la Comunicación Colectiva es hacer referencia a la intencionalidad de los mismos una vez han llegado a su destino. Un mensaje no es mas que "una secuencia de signos transmitidos entre un emisor y un receptor por medio de un canal que constituye el soporte físico indispensable para la transmisión" (Balle, 1991). Ante esta definición nos planteamos cuál es la verdadera función del mismo, es decir, cuándo adquiere una forma concreta para ser transmitido. Podemos leer que:

"El mensaje se convierte en algo real y tangible cuando un contenido de pensamiento o de conciencia adquiere una forma concreta de acuerdo con las normas convencionales de un determinado código (o conjunto de signos)" (Martínez Albertos, ,1997).

Sea como sea, debemos tener en cuenta que los mensajes, independientemente de su código, su canal, su emisor y receptor y al margen de todos los agentes tangibles e intangibles que intervengan en el proceso creativo, gozan de una funcionalidad, a saber, una intencionalidad que va más allá del mero proceso de transmisión de la información y que introduce una función lingüística que es la que le aporta la finalidad.

En el contexto de nuestra investigación los mensajes son las propias noticias, es decir, el carácter, texto y forma de cada una de las inserciones que configuran el suplemento Paraninfo. Después de haber visto cuáles son los temas que se barajan en la creación de la agenda setting de la publicación de la Universidad de Alicante y haber clasificado los públicos a los que se dirige cada una de las noticias, creemos conveniente hacer una reflexión acerca de cuál es la finalidad de estos mensajes, es decir, qué se pretende con ellos, cuál es su objetivo final, si se trata, por consiguiente, de informar acerca del estado de la Institución, de persuadir a los públicos o simplemente de divulgar el conocimiento científico que en esta comunidad se genera. 
Debemos tener en cuenta que a la hora de establecer los patrones que guían una distribución temática, es necesario definir la intencionalidad de la misma. Es decir, la estrategia comunicativa no puede limitarse a la distribución puramente informativa de los temas seleccionados y mucho menos establecerse como un patrón unidireccional sobre el cual emitir noticias sin intencionalidad. Al contrario, es evidente que los mensajes que se emiten en este canal -y en cualquier otro que forme parte de la vía de comunicación de la Universidad- goza de una funcionalidad, bien sea meramente informativa, persuasiva, publicitaria o corporativa, para contribuir a la buena imagen de la Institución y contribuir a la imagen de marca de la misma.

En cualquier caso, para dar coherencia y un alcance general a las conclusiones de este análisis de contenido es necesario contemplar la finalidad de las noticias emitidas con la intención de poder poner de manifiesto una aproximación teórica empírica que nos acerque a la estrategia comunicativa fundamental de la institución en cuestión. Para ello, hemos definido cuatro categorías básicas de clasificación de la finalidad de los mensajes que nos permiten establecer una tipología acerca de las noticias analizadas. Las categorías de análisis que hemos definido son las siguientes:

- Informativa: las noticias cuya finalidad hemos clasificado como informativa son aquellas que pretenden acercar la información al lector, ya sea un lector interno, general o vinculado. Estas noticias se caracterizan por gozar de una función referencial a través de la cual se pretende dar constancia de un hecho -pasado o futuro- con un mero alcance informativo.

- Divulgativa: las noticias categorizadas como divulgativas responden a la lógica de hacer llegar el saber a los públicos de toda índole. Se trata de noticias que, por su contenido, buscan poner de manifiesto un avance científico, bien surgido de la actividad universitaria, bien un avance general. En cualquier caso, la funcionalidad de estas noticias pretende ofrecer un conocimiento nuevo al lector.

- Publicitaria: la finalidad publicitaria define a aquellas noticias que pretenden, sea directa o indirectamente, hacerse eco de un acontecimiento o producto desde una perspectiva comercial. En esta categoría hemos incluido tanto los propios anuncios, como las noticias que hacen referencia a bienes/servicios susceptibles de ser consumidos por el receptor.

- Corporativa: son aquellas noticias que pretenden contribuir a la buena imagen de la institución, entendiendo esta como una organización empresarial que funciona. Se trata de noticias que, más allá de informar acerca del status quo de la institución pretenden contribuir a que la percepción sobre la Universidad sea positiva, poniendo de manifiesto los logros y alcances de la misma.

No obstante como se ha establecido inicialmente, y con independencia de la finalidad del mensaje, las propias particularidades del contenido informativo en cada caso también pueden 
influir, en mayor o menor medida, en la opinión del lector acerca de la Universidad y en el respectivo posicionamiento de su marca.

Los resultados expresados en porcentajes, se pueden visualizar en los siguientes diagramas de sectores (imágenes 12, 13, 14, 15 y 16):

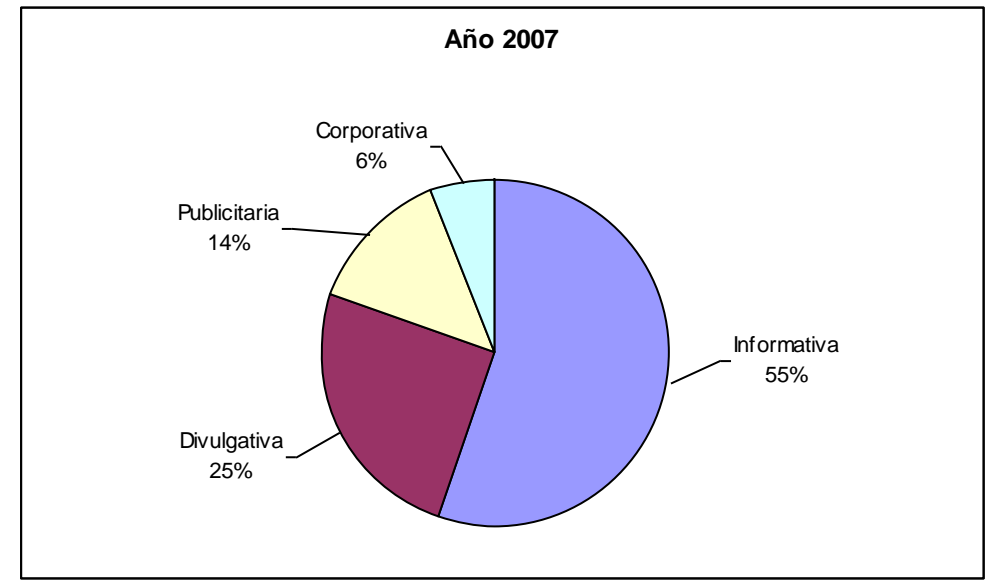

Imagen 12: Finalidad de los mensajes año 2007

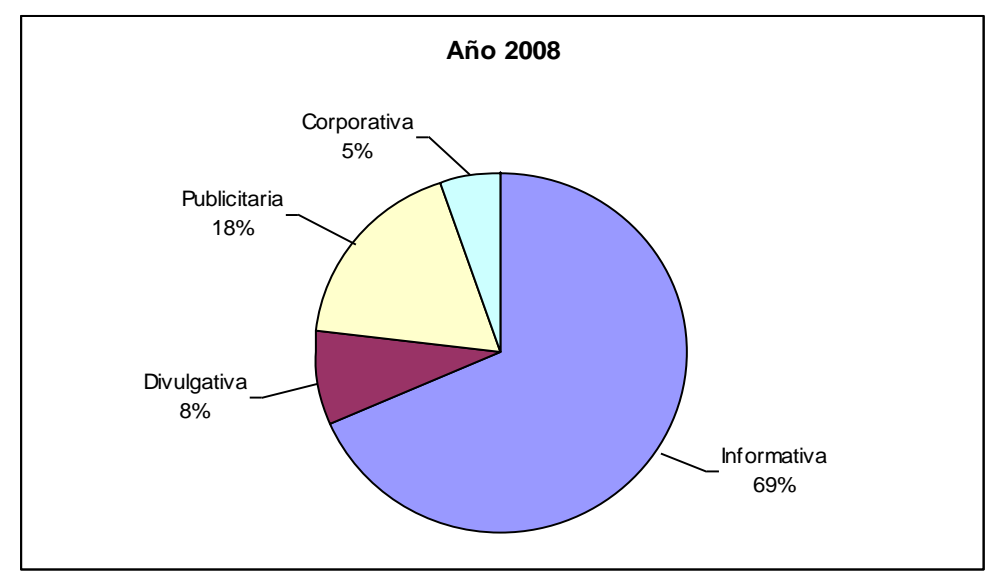

Imagen 13: Finalidad de los mensajes año 2008 


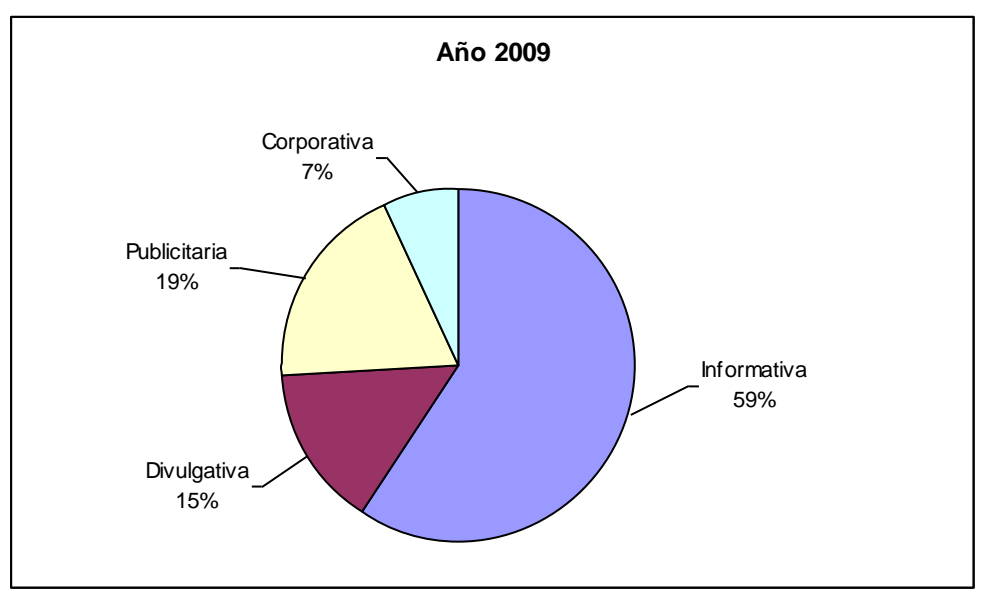

Imagen 14: Finalidad de los mensajes año 2009

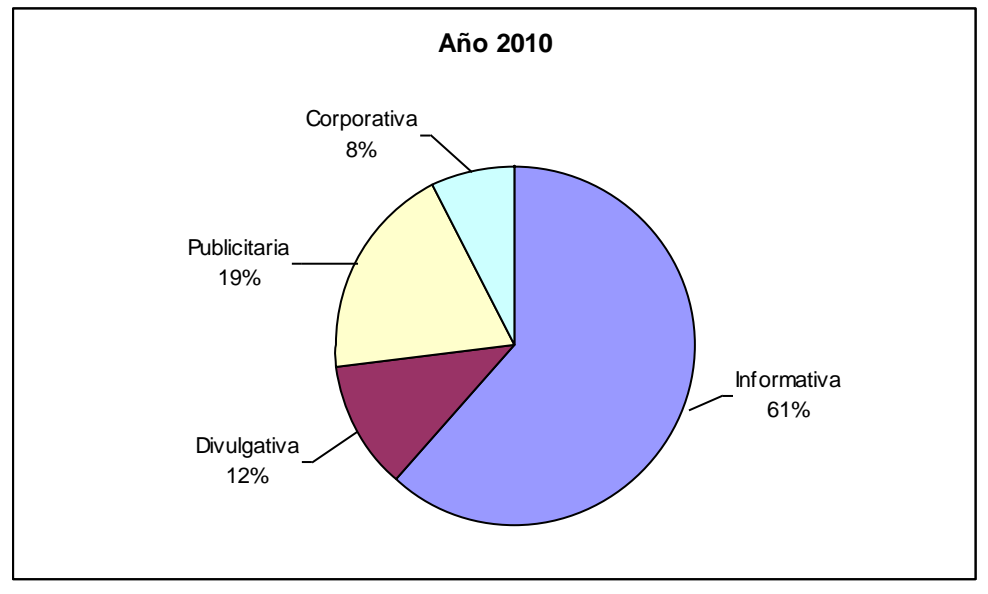

Imagen 15: Finalidad de los mensajes año 2010

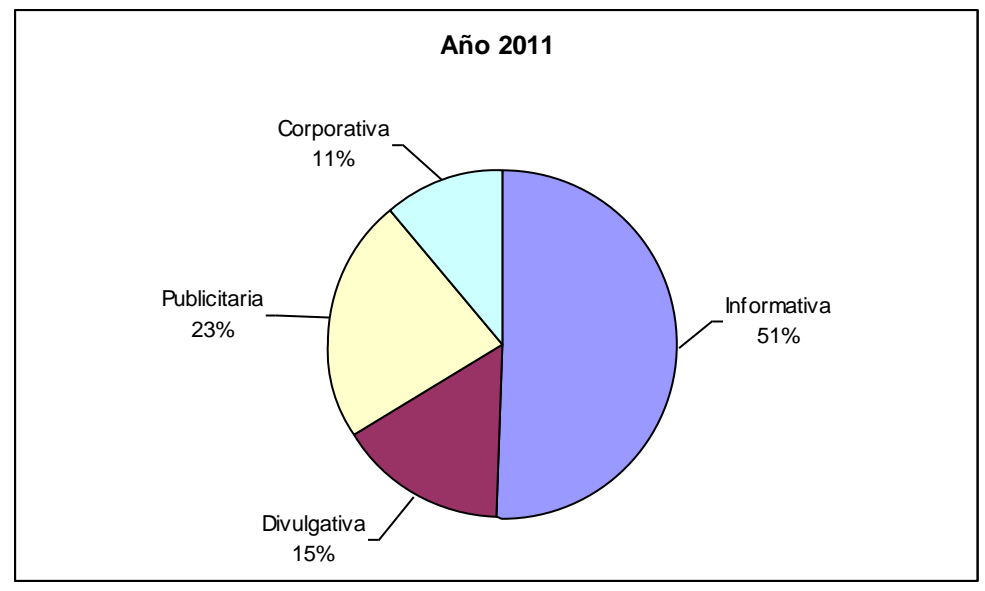

Imagen 16: Finalidad de los mensajes año 2011 


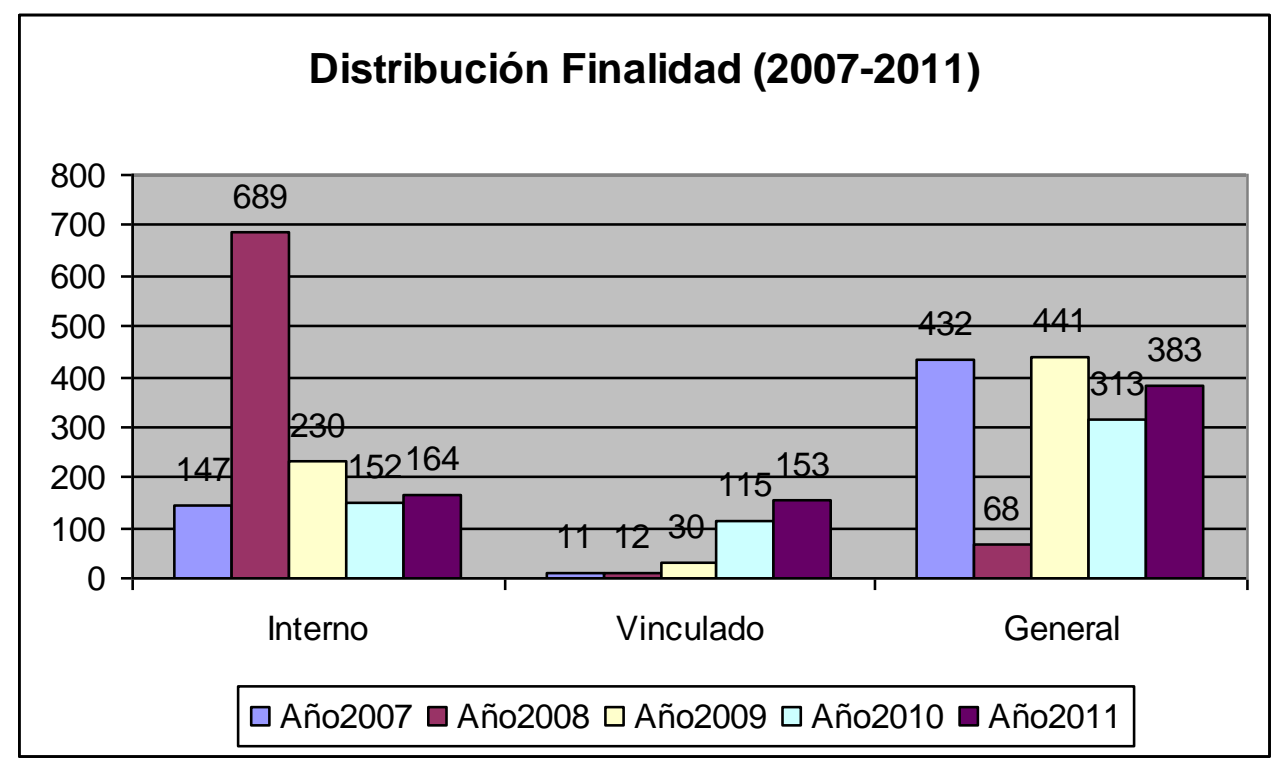

Imagen 17: Evolución de la finalidad de los mensajes (Año 2007-2011).

Si tenemos en cuenta las conclusiones del análisis de contenido observamos que, a priori, la finalidad fundamental de las noticias que configuran la agenda setting de la Universidad en el suplemento Paraninfo es informativa. Debemos de tener presente que el sustento del boletín informativo que analizamos pretende ser una herramienta que mantenga un vínculo directo entre la Universidad y sus públicos. Por este motivo, no resulta extraño que la mayoría de noticias se destinen a un fin informativo. Observamos que en 2007, por ejemplo, las noticias informativas representaban en $55 \%$ del total, frente a un $69 \%$ en 2008 , un $59 \%$ en 2009 , un $61 \%$ en 2010 y asentándose en un 51\% en 2011. A pesar de las variaciones en los porcentajes obtenidos, observamos que las noticias emitidas responden a una lógica constante en la que prima la información ante el resto de categorías. Las variaciones resultan insignificantes si tenemos en cuenta el todo del corpus analizado.

Ahora bien, a pesar de que la función informativa es la que más peso adquiere en las noticias analizadas, debemos destacar, en primer lugar, la situación particular de las noticias divulgativas. Nos encontramos con una categoría que tras ocupar un 25\% en el año 2007 y tras una pequeña subida en el año 2009, está en constante decrecimiento. Este decrecimiento no es alarmante pero si representa una realidad que afirma que la tendencia en la representación de noticias con finalidad de divulgación del conocimiento es cada vez inferior y tiende a la baja. Además, este dato va en concordancia con la tendencia decreciente a representar en la agenda setting noticias vinculadas con la divulgación científica. Resulta curioso como, en un momento en el que la divulgación de la ciencia es cada vez más importante en el contexto socialv, desde la Universidad se obvia esta realidad y se retrocede en este sentido.

En cuanto a las noticias con una finalidad publicitaria observamos que existe un equilibrio parcial en los tres primeros años de análisis, representando un $14 \%$ en el primer año, un 18\% 
en el 2008 y un 19\% en 2009. A partir de 2010, las noticias con finalidad publicitaria empiezan a estar más presentes y se muestran en crecimiento constante, representando un 19\% del total en 2010 y un $23 \%$ en 2011.

Por lo que respecta a la finalidad corporativa, aquella que contribuía a la consolidación de la imagen de la organización y permite una percepción positiva de la misma se mantiene prácticamente constante, representando un $6 \%$ del total en 2007 , un pequeño descenso en 2008 con un 5\%, un 7\% en 2009 y a partir de 2010 y 2011 se muestra en constante crecimiento, representando un 8 y un 11\%, respectivamente. Este hecho nos permite afirmar que, desde la Universidad, cada vez se tiene más en cuenta la imagen de marca institucional como una de las vías a potenciar a través de la comunicación. Se trata de conseguir que la Universidad sea percibida públicamente y como un ente solidario, efectivo y actual a través de la proyección una imagen positiva y transparente de la Institución que también contribuya a aumentar el valor estratégico de la marca UA.

"La acción, el acto o la actuación no pueden explicarse por sí mismos; no pueden transmitir la información, el significado y los valores que contienen, y que la empresa quiere acentuar, mostrar y trasferir a sus públicos destinatarios. El fenómeno, o el acto, no se explica por sí sólo, simplemente los individuos lo perciben porque «ocurre», y lo interpretan a su manera, aunque no siempre como la empresa quisiera. Además la percepción del hecho es una experiencia individual, y cada uno le da su sentido, hace su interpretación subjetiva, filtrada psicológicamente. La acción se socializa con la comunicación”. (Costa, 1999)

La tendencia, al igual que en las organizaciones es generar todo un conglomerado de información corporativa que permitan la aceptación total de la imagen de la institución en la sociedad. De este modo, y a pesar que el crecimiento no es extremadamente grande, si que observamos una tendencia que confirma la necesidades patentes de la Institución.

Observamos, pues, en síntesis, que la finalidad fundamental de las noticias que forman parte de este análisis se caracterizan por representar un carácter informativo, a pesar de que cada vez más, la tendencia corporativista y publicitaria se van abriendo hueco en el abanico comunicativo del suplemento.

\section{Conclusiones}

Después de la exposición de los resultados del análisis de contenido del suplemento Paraninfo de la Universidad de Alicante, podemos decir que nos encontramos frente a una publicación informativo con cierto carácter institucional, cuyos públicos principales son los generales y la finalidad de las noticias del mismo es, mayoritariamente, informativa y corporativa. 
Ante esta afirmación general que engloba los resultados principales de la investigación, debemos hacer ciertos matices que ayudan a entender mejor y más profundamente la morfología del suplemento analizado y su carácter formal.

Si hablamos de las temáticas que sustentan el suplemento y las cuales constituyen la agenda setting del mismo, debemos decir que se trata de una publicación en el que las noticias culturales tienen mucho peso. A pesar de no tratarse de un boletín cultural, se dedica mucho espacio a las noticias relacionadas con la cultura, bien a modo informativo, bien como divulgación de las propias actividades que se organizan desde la Universidad de Alicante. Los datos porcentuales (recordemos que la cultura suele ocupar alrededor del 30 y $40 \%$ del total de las noticias insertadas) nos confirman la importancia de esta categoría temática, permitiendo afirmar que el boletín informativo en cuestión goza de cierto carácter cultural evidente y diferenciable.

Al margen de las noticias culturales, es necesario mencionar la importancia creciente de las noticias informativas. El suplemento, que nace como una herramienta de comunicación entre la Universidad y sus públicos, adquiere evolutivamente un carácter cada vez más institucional, que busca mejorar la imagen de la Universidad en la sociedad y contribuir a una percepción positiva por parte de los públicos. No podemos afirmar que se trate de un boletín institucional, puesto que este tipo de noticias en ningún caso supera el 20\% del contenido total, pero si debemos dejar constancia de la evolución constante y evidente de esta temática, que pasa de ocupar un 6\% de la totalidad de noticias emitidas en 2007 a un 18\% en el año 2011.

Otra conclusión sólida que surge del estudio planteado recae en la importancia creciente de las noticias publicitarias en el seno de la publicación analizada. La publicidad, bien en formato tradicional o bien como publirreportajes u otras fórmulas contempladas no ocupaba un lugar relevante en la distribución temática del primer año de análisis (sólo un 13\% de las noticias analizadas en 2007 respondían a este carácter). No obstante, observamos un crecimiento prolongado a lo largo de los cinco años de estudio, situándose el dato final en un $23 \%$ del total de las noticias analizadas en el año 2011. Aunque sabíamos a priori que el boletín en cuestión no era una herramienta publicitaria, resulta curioso observar cómo esta categoría se encuentra en constante crecimiento y la relacionamos con la importante crecida de la comunicación institucional. Sería interesante que, un estudio posterior, analizara la relación entre la creciente importancia institucional en los temas de la agenda setting del suplemento con el crecimiento del contenido publicitario ( $y$, en concreto, autopublicitario) para establecer si existe relación entre esta tendencia y si ambos forman parte de una misma estrategia institucional.

Además, nos parece necesario mencionar que existe un descenso considerable en la presencia de noticias relacionadas con la divulgación científica. Según los datos del estudio, la divulgación de la ciencia ocupaba un 19\% del total en el año 2007 y en 2011 sólo ocupa un 10\% del total de noticias analizadas. Este dato nos hace pensar que la Universidad está descuidando parcialmente la divulgación de la ciencia en general y de sus propios avances investigadores en 
particular. Es extraño que en un contexto en el que la divulgación científica está teniendo cada vez más importancia tanto en televisiones como en otros medios de comunicación, la Universidad no parece tener establecida una estrategia comunicativa frente a este tema. Nos parece un descuido ya que, por una parte, las noticias de este carácter tendrían gran acogida entre los públicos -siguiendo las tendencias sociales generales- y, en segundo lugar, porque se dejan de comunicar avances y resultados que surgen desde la propia Universidad y que, por consiguiente, supondrían una ventaja competitiva para la imagen institucional de la misma.

En cuanto al resto de categorías analizadas, no nos ofrecen datos relevantes ya que ocupan espacios menos significativos y además se representan de manera constante, sin altibajos en su presencia global.

Si hablamos de los públicos a los que se dirige el suplemento, debemos decir que se trata de un boletín que, mayoritariamente, se dirige a la sociedad en general. Es decir, el suplemento Paraninfo se aleja de ser una herramienta de comunicación interna para acercarse más a una herramienta de comunicación general que busca llegar más allá de los muros de la Universidad para acercarse a todos los públicos. No obstante, y a pesar de que entre el 50 y el 70\% del total de las noticias analizadas se dirigen a un público general, debemos destacar que existe un porcentaje gradual destinado a los públicos internos, que oscila entre el 25 y el $35 \%$. Cabe decir que el año 2008 representa un hecho aislado en la tendencia representativa de los públicos, ya que los mensajes dirigidos a los públicos internos ocupaban un $89 \%$ de las noticias analizadas. Este hecho encuentra su explicación en la existencia de elecciones ese mismo año, motivo por el cual desde la institución se potenció la comunicación con sus públicos internos con la intención de mejorar su flujo comunicativo y hacer llegar a estos mensajes susceptibles de favorecer las elecciones generales de la Universidad.

A parte de los públicos generales y los internos, cabe destacar la existencia de mensajes que se dirigen a agentes vinculados. Estos stakeholders, que en los primeros años de análisis no ocupaban más del $5 \%$ del total de noticias analizadas, se han convertido en públicos presentes en la estrategia de comunicación de la Universidad, ya que han llegado a ocupar un 20 y un $22 \%$ del total de noticias analizadas en los dos últimos años de análisis.

Si hablamos de la finalidad de los mensajes debemos decir, tal y como se ha justificado en los gráficos adjuntos, que más de la mitad de las noticias analizadas responden a una finalidad informativa. Con algún altibajo a lo largo de los años, las noticias con una de este tipo ocupan entre el 50 y el $70 \%$ del total analizado. Se trata de un dato representativo puesto que podemos afirmar que, a pesar de la tendencia institucional del suplemento, se mantiene constante el significado original del mismo que pretendía ser una herramienta informativa entre la Universidad y el mundo exterior. Ahora bien, no podemos obviar, tal y como se ha justificado en el análisis la importancia creciente de las noticias con una finalidad publicitaria, que ha pasado de ocupar un 14\% en el año 2007 a un 23\% en el último año de análisis. 
Esta tendencia creciente va en concordancia con la mayor importancia de las noticias con carácter publicitario y nos confirma que el suplemento cada vez reserva más espacio para la publicidad bien sea comercial o bien autopublicitaria y que, por tanto, ve en ésta no solo la ventaja económica que generan sus ingresos sino también una herramienta de autopromoción interesante a la hora de establecer una imagen corporativa de la propia Universidad. En este sentido, debemos destacar la existencia de noticias cuya finalidad responde a una necesidad corporativa. Ya en el año 2007 detectamos que un 6\% del total de noticias buscaban este objetivo. Tras un crecimiento constante, se sitúa en el año 2011 en un $11 \%$.

Este hecho se interrelaciona con la finalidad publicitaria y con el propio carácter institucional de la agenda setting ya que busca contribuir a la imagen de la Universidad como institución poniendo de manifiesto la necesidad de velar por una imagen positiva y bien percibida por parte de los públicos. Vemos, por tanto, que tanto el crecimiento publicitario como el crecimiento corporativo de los mensajes no es banal, sino que se relacionan con la propia tendencia institucional que pretende contribuir a la mejora de la imagen pública de la Universidad y al afianzamiento de la marca "UA".

En definitiva, podemos afirmar que nos encontramos ante un suplemento que, a pesar de nacer con un claro objetivo informativo, se ha ido acercando a posiciones cada vez más institucionales, tanto a través del contenido de las noticias del mismo como de los públicos a los que se dirige y/o la finalidad de los propios mensajes. Aunque no podemos decir que se trate de un boletín corporativo, sí que es necesario recalcar que cada vez más, la esencia informativa del propio suplemento se acerca más al corporativismo, siguiendo las tendencias generales de la comunicación institucional. Además, y para finalizar, afirmamos que se trata de una herramienta comunicativa que, a parte de informar y mantener a los públicos al corriente de la realidad universitaria, pretende fidelizar a los mismos plasmando una imagen corporativa positiva de la Universidad a través de sus ocho páginas semanales. 


\section{Bibliografía}

Anderson, P. (1982): "Marketing, strategic planning, and the theory of the firm". Journal of Marketing, $\mathrm{n}^{\circ} 42,15-26$.

Baez Padrón, G. (2010), "La participación protagónica estudiantil en el proceso de extensión universitaria”. Revista Latinoamericana de Ciencias Sociales, Niñez y Juventud, vol. 8, n 1 , pp.

Balle, F. (1991): Comunicación y sociedad: evolución y análisis comparativo de los medios. Bogotá: Tercer Mundo.

Berelson, B. (1952): Content Analysis in Communication Researches. Glencoe III: Free Press.

Costa J. (1999): La comunicación en acción: Informe sobre la nueva cultura de la gestión. Barcelona: Paidós.

De Aguilera Moyano, M. et al. (2010): "La comunicación universitaria: Modelos, tendencias y herramientas para una nueva relación con sus públicos". Revista Icono 14, año 8, vol.2, n¹4, pp. 90-124. Recuperado (23 de junio de 2012) de http://www.icono14.net.

Freeman, R. E (1984): Strategic management: A stakeholder approach. Pitman Press: Boston

Friedman, A. y Miles, S. (2006): Stakeholders: Theory and Practice. Oxford: Oxford University Press.

García Rivas, M. (2003): "Presente de la información institucional de la Universidad española. El caso de la Universidad de Murcia.". Comunicación y Sociedad, vol.16, no 1, pp 29-56.

Lippmann, W. (2003): La opinión pública. Madrid: Langre.

Losada Vázquez, A. (1998): La comunicación institucional en la gestión del cambio. El modelo universitario. Salamanca: Universidad Pontificia de Salamanca.

Martínez Albertos, J.L. (1992): Curso General de Redacción Periodística. Edición revisada. Madrid: Paraninfo/Thomson Learning (1997): El ocaso del Periodismo. Barcelona: CIMS.

.McCombs, M. (1994): "The future agenda for agenda-setting research". Journal of Mass Communication Studies, $\mathrm{n}^{\circ} 45$, p. 171-181 
(1996): "Influencia de las noticias sobre nuestras imágenes del mundo". En Bryant, J. y Zillmann, D. (1996): Los efectos de los medios de comunicación. Investigaciones y teorías. Barcelona: Paidos. pp. 13-34.

McCombs, M y Shaw, D. (1972): "The agenda-setting function of mass media". Public Opinion Quarterly, vol.36, n², pp. 176-187.

Murcia Peña, N. (2009): "Vida universitaria e imaginarios: posibilidad en definición de políticas de educación superior”. Revista Latinoamericana de Ciencias Sociales, Niñez y Jwentu, vol. 6, $\mathrm{n}^{\circ}$ 2, pp. 235-266.

Pérez C.C. y Salinas G. (2008). Valoración y evaluación de marcas. Ediciones Deusto.

Reavill, L. (1998): "Quality assessment, total quality management and the stakeholders in the UK higher education system". Managing Service Quality, vol. 8, n 1, pp.55-63.

Rodrigo Alsina, M. (1996): La construcción de la noticia. Barcelona: Paidós.

Rodríguez Díaz, R. (2004): Teoría de la Agenda Setting, aplicación a la enseñanza universitaria. Alicante: OBETS.

Tonon, G. (2012): "Las relaciones universidad-comunidad: un espacio de reconfiguración de lo público". Revista Polis [En línea], no 32. Recuperado (29 de septiembre de 2012) de: http://polis.revues.org/6691; DOI : 10.4000/polis.669.

Van Dijk, T. A. (1990): La noticia como discurso. Barcelona: Paidós.

Wolf, M. (1987): La investigación de la comunicación de masas. Barcelona: Paidos

Wolfe, R. A. y Putler, D. S. (2002): "How Tight are the Ties that Bind Stakeholder Groups?”. Organizational Science, vol. 13 n 1, pp. 64-82. 


\section{(a) (1) ( () \\ Licencia Creative Commons \\ Miguel Hernández Communication Journal \\ mhcj.es}

Forma de citar este artículo en las bibliografías

Tatiana Hidalgo-Marí, Eliseo Rodríguez-Monteagudo (2013): “La tipología de los mensajes en el suplemento "Paraninfo" de la Universidad de Alicante: temáticas, públicos objetivos y finalidad de los mensajes", en Miguel Hernández Communication Journal, nº, páginas 31 a 64. Universidad Miguel Hernández, UMH (Elche-Alicante). Recuperado el — de de 20 de: http: $/ /$ mhcj.es. $/$ index.php?journal $=$ mhcj\&page $=$ article\&op $=$ view\&path $\% 5 \mathrm{~B} \% 5 \mathrm{D}=3$

ii Según datos consultados en el último Estudio General de Medios (EGM) que afecta a nuestra investigación (tercer año móvil correspondiente a febrero-noviembre de 2011), el Diario Información cuenta con una media de 244000 lectores diarios en su zona de alcance (provincia de Alicante). La Oficina de Justificación de la difusión (OJD) indica en su última oleada de control (año 2011) que el Diario Información gozó de una tirada media de 30009 ejemplares, el promedio de difusión de la cual se sitúa en 25022.

iii Debemos tener en cuenta que el año 2008 es un año de elecciones universitarias, que se celebran cada cuatro años. Es lógico, por tanto, que en este período (sobre todo en el primer semestre del año en cuestión) se dedicara mucho más espacio para dirigirse a la comunidad interna universitaria, ya que son los que tienen el poder de decisión ante el proceso electoral.

iv Recordemos que los datos del Estudio General de Medios expuestos anteriormente afirmaban una media de 244000 lectores diarios.

${ }^{\vee}$ En el contexto social y comunicativo es evidente que cada vez más la divulgación científica ocupa un lugar privilegiado en el seno de los medios de comunicación. Programas que pretenden acercar la ciencia a la población llana, personajes prescriptores que distribuyen el conocimiento, plataformas que velan por la correcta divulgación de los avances científicos y tecnológicos y un sin fin de acciones que pretenden que la ciencia y los avances en este sentido sean cada vez más una realidad comprensible por los públicos. 